\title{
An Integrated Model of Tritium Transport and Corrosion in Fluoride Salt- Cooled High-Temperature Reactors (FHRs) - Part I: Theory and Benchmarking
}

\author{
John D. Stempien*, Ronald G. Ballinger, and Charles W. Forsberg \\ Department of Nuclear Science and Engineering, Massachusetts Institute of Technology, \\ 77 Massachusetts Ave, Cambridge, MA 02139
}

\begin{abstract}
The Fluoride Salt-Cooled High-Temperature Reactor (FHR) is a pebble bed nuclear reactor concept cooled by a liquid fluoride salt known as "flibe" $\left({ }^{7} \mathrm{LiF}_{-} \mathrm{BeF}_{2}\right)$. A model of TRITium Diffusion EvolutioN and Transport (TRIDENT) was developed for use with FHRs and benchmarked with experimental data. TRIDENT is the first model to integrate the effects of tritium production in the salt via neutron transmutation, with the effects of the chemical redox potential, tritium mass transfer, tritium diffusion through pipe walls, tritium uptake by graphite, selective chromium attack by tritium fluoride, and corrosion product mass transfer. While data from a forced-convection polythermal loop of molten salt containing tritium did not exist for comparison, TRIDENT calculations were compared to data from static salt diffusion tests in flibe and flinak (0.465LiF$0.115 \mathrm{NaF}-0.42 \mathrm{KF}$ ) salts. In each case, TRIDENT matched the transient and steady-state behavior of these tritium diffusion experiments. The corrosion model in TRIDENT was compared against the natural convection flow-loop experiments at the Oak Ridge National Laboratory (ORNL) from the 1960s and early 1970s which used Molten Salt Reactor Experiment (MSRE) fuel-salt containing $\mathrm{UF}_{4}$. Despite the lack of data required by TRIDENT for modeling the loops, some reasonable results were obtained. The TRIDENT corrosion rates follow the experimentally observed dependence on the square root of the product of the chromium solid-state diffusion coefficient with time.

Additionally the TRIDENT model predicts mass transfer of corrosion products from the hot to the cold leg (as was observed in the experiments with salts containing $\mathrm{UF}_{4}$ ). In a separate paper the results of TRIDENT simulations in a prototypical FHR are presented.
\end{abstract}

Keywords: tritium, tritium transport, corrosion, FHR, flibe, molten salt, fluoride salt, MSR, MSRE

\section{Introduction}

A unique model of TRItium Diffusion Evolution and Transport (TRIDENT), the first such model to integrate the effects of tritium transport, reactor coolant chemistry, and corrosion phenomena, was developed and benchmarked (Stempien, 2015). This paper highlights the important dependencies captured in TRIDENT, and reports the results of benchmarking comparisons.

Forsberg, et. al. have proposed a new type of reactor: one which combines the graphite-matrix, coated-particle fuel developed for gas-cooled reactors with the fluoride salt coolant used in the 1960s 
Molten Salt Reactor Experiment (MSRE) at Oak Ridge National Laboratory (ORNL) (Forsberg et al., 2003). Originally called the Advanced High-Temperature Reactor (AHTR), this concept is now known as the fluoride salt-cooled high-temperature reactor (FHR). Interest from the U.S.

Department of Energy (DOE) has enabled universities and national laboratories to engage in research and development related to FHRs (Forsberg et al., 2013; Holcomb et al., 2013). What distinguishes an FHR from a molten salt reactor (MSR) is that an MSR dissolves the fuel directly in the coolant, but an FHR utilizes a solid fuel with a clean (un-fueled) coolant-salt. The baseline FHR coolant is a lithium-fluoride beryllium-fluoride salt called flibe $(0.67$ mole fraction $\mathrm{LiF}-0.33$ mole fraction $\mathrm{BeF}_{2}$ ) which utilizes lithium enriched in the Li-7 isotope. Flibe melts at $459{ }^{\circ} \mathrm{C}$ and boils at $1430{ }^{\circ} \mathrm{C}$.

There are a number of potential core configurations and fuel types that might be compatible with an FHR, but the baseline commercial design (called the Mk1 PB-FHR) utilizes a pebble bed core with online refueling (Andreades et al., 2014). While the FHR has numerous potential capabilities, configurations, and applications, in order to commercialize it, a compelling economic and technical case must be made if FHRs are to become viable candidates for next-generation power systems. The current commercial case for the FHR is that it enables a nuclear and renewable electric grid and increases revenue by $50 \%$ or more compared to base-loaded, light water reactor (LWR) nuclear plants (Forsberg et al., 2013, 2014a). This is a consequence of coupling the reactor to a Nuclear airBrayton Combined Cycle (NACC) that enables the production of base-load electricity and peak electricity using auxiliary natural gas, stored heat, or hydrogen. The open-air NACC power cycle is similar to that used in natural gas combined-cycle plants. This specific design is based on the GE 7FB gas turbine. NACC heat exchangers have hot coolant salt on one side and compressed air on the other side; thus, any tritium diffusing through the heat exchanger will exit via the gas turbine exhaust. This is in contrast to closed power cycles (steam, supercritical carbon dioxide, etc.) where tritium can be trapped in the power cycle. Economic considerations favor an FHR with NACC but also impose added requirements for tritium control and thus increase the importance of modeling tritium behavior.

The FHR possesses a number of appealing characteristics including coolant outlet temperatures of at least $700{ }^{\circ} \mathrm{C}$ and a number of inherent and engineered passive safety features. Major inherent safety features are due to the design of the coated particle fuel, which is stable to greater than 1600 ${ }^{\circ} \mathrm{C}$, and the high boiling point of the coolant, which exceeds $1400{ }^{\circ} \mathrm{C}$. These properties would enable the FHR to operate at atmospheric pressure with hundreds of degrees of margin to fuel damage and coolant boiling (Forsberg et al., 2014b). Major engineered passive safety features include the use of a pool-type vessel and a natural circulation decay heat removal system activated passively by a fluidic diode.

No FHR has ever been built, and uncertainties will need to be addressed before either a test or commercial reactor can be constructed. The MSRE operated at ORNL in the 1960s using uranium fuel dissolved in the $\mathrm{LiF}_{-} \mathrm{BeF}_{2}$ coolant (Haubenreich and Engel, 1970). The issue of tritium production in this coolant was only realized at the end of the MSRE program. Tritium production rates, tritium release rates, and tritium distribution throughout an FHR are currently unknown. 
Corrosion rates are uncertain because they couple to tritium behavior (Calderoni et al., 2009) and are sensitive to the presence of impurities within the coolant (Keiser et al., 1977). In order to address these uncertainties, a unique model of TRItium Diffusion Evolution and Transport (TRIDENT) integrating the effects of tritium transport, reactor coolant chemistry, and corrosion phenomena was developed and benchmarked (Stempien, 2015). This paper highlights the important dependencies captured in TRIDENT and reports the results of benchmarking comparisons. Results from TRIDENT simulations of a prototypical pebble-bed FHR are presented in a separate article.

\section{TRIDENT reactor system model description}

A high-level flow chart for the TRIDENT model is given in Fig. 1. Tritium is born in the coolant as dissolved TF (see Section 3). Depending on the chemical redox condition of the coolant (defined by the fluorine potential described in Section 4) tritium will speciate into both $\mathrm{TF}$ and $\mathrm{T}_{2}$ via chemical reactions. The fluorine potential in the coolant determines the thermodynamic driving force for corrosion and the relative amounts of $\mathrm{TF}$ and $\mathrm{T}_{2}$ in the system. Both $\mathrm{TF}$ and $\mathrm{T}_{2}$ can be adsorbed on graphite in the core depending on the mass transport parameters and graphite capacity for tritium. In FHRs, tritium behavior is intimately linked with corrosion (see Sections 4 and 6). Tritium born in the coolant as TF can corrode structural metals, and a byproduct of these reactions is

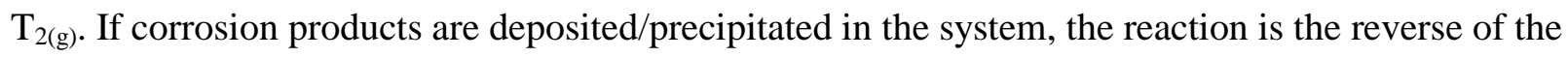
corrosion reaction, and $\mathrm{TF}$ is generated as $\mathrm{T}_{2}$ is consumed. Corrosion control is based on mitigating selective chromium attack by TF, and the radiological management of tritium is based on preventing unwanted diffusion/migration of $\mathrm{T}_{2}$ through system boundaries. TRIDENT couples the redox potential to $\mathrm{TF} / \mathrm{T}_{2}$ speciation, allowing it to realistically predict tritium buildup in the reactor, relevant corrosion reactions, tritium trapping on graphite, and tritium diffusion through system barriers. If desired, TRIDENT can simulate different engineered mechanisms for $\mathrm{TF}$ and $\mathrm{T}_{2}$ removal from the coolant (such as gas-stripping, permeation windows, sorption on beds of carbon, etc. discussed in a separate paper). Only $\mathrm{T}_{2}$ can diffuse through metal. Thus, only $\mathrm{T}_{2}$ is allowed to diffuse out of the primary system through the heat exchangers in the model. TRIDENT is capable of simulating single loop reactors or two-loop reactors having both a primary and secondary system. Any tritium not escaping through the heat exchangers or not removed by engineered systems is then returned to the core through the core coolant inlet. 


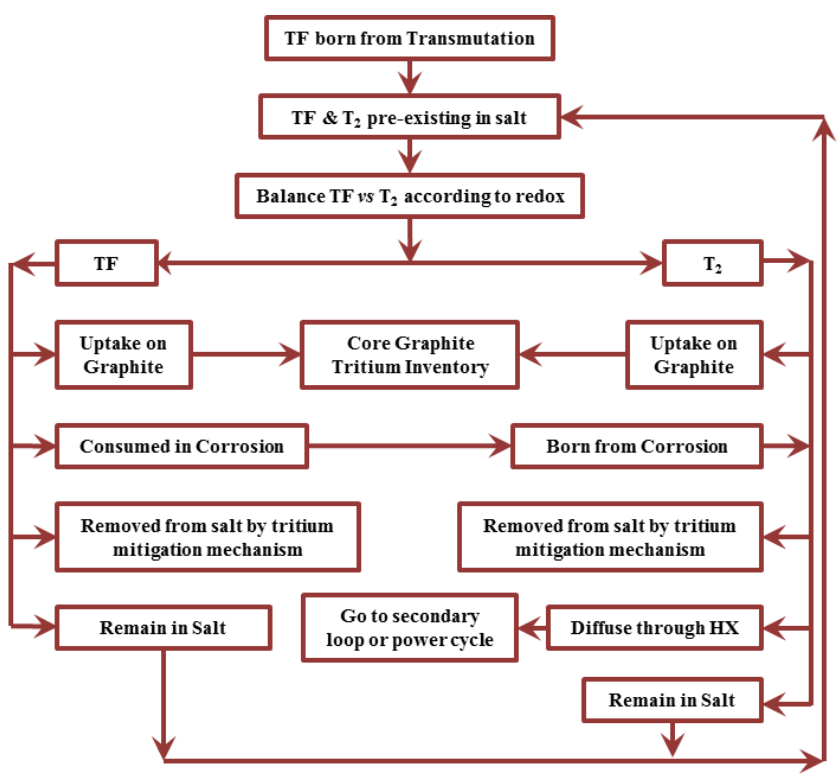

Fig. 1. TRIDENT model flow chart.

\section{Tritium Production in FHRs}

Any beryllium or lithium-based salt reactor coolant will generate tritium due to neutron transmutation. Eq. (1) through Eq. (5) show the major pathways for tritium production in flibe. Although the baseline FHR coolant is flibe enriched to $99.995 \mathrm{wt} \%$ in $\mathrm{Li}-7$, the remaining $0.005 \mathrm{wt} \%$ Li-6 poses a significant problem because it produces tritium via an $n, \alpha$ reaction with thermal neutrons. The Li- 6 cross section for this reaction follows a $1 / v$ dependence and reaches nearly 5,000 barns at low neutron energies. The Li- $7 n, n$ ' reaction is a fast neutron reaction occurring only with neutron energies above $0.546 \mathrm{MeV}$. The reaction in F-19 only occurs for neutron energies greater than $9.5 \mathrm{MeV}$; thus, the contribution from this reaction is minimal in MSRs and especially minimal in FHRs (Briggs, 1971; Ingersoll et al., 2004). The n, $\alpha$ reaction in Be-9 does not generate T directly; however, it does generate He-6, which decays with a 0.8 second half-life into new Li- 6 . Thus, the initial $0.005 \mathrm{wt} \%$ of Li-6 in flibe can be consumed by neutron transmutation, but additional Li- 6 is continually produced by neutron transmutation in Be-9. This means that the rate of tritium production will vary through the reactor life (assuming the coolant is not replaced with fresh flibe).

$$
\begin{gathered}
{ }^{6} \mathrm{LiF}+n \rightarrow{ }_{2}^{4} \mathrm{He}+{ }_{1}^{3} \mathrm{HF} \\
{ }^{7} \mathrm{LiF}+n \rightarrow{ }_{2}^{4} \mathrm{He}+{ }_{1}^{3} \mathrm{HF}+n^{\prime} \\
{ }_{9}^{19} \mathrm{~F}+n \rightarrow{ }_{8}^{17} \mathrm{O}+{ }_{1}^{3} \mathrm{H} \\
{ }_{4}^{9} \mathrm{BeF}_{2}+n \rightarrow{ }_{2}^{4} \mathrm{He}+{ }_{2}^{6} \mathrm{He}+2 \mathrm{~F} \\
{ }_{2}^{6} \mathrm{He} \rightarrow{ }_{3}^{6} \mathrm{Li}+e^{+}+\bar{v}_{e} \quad\left(t_{1}=0.8 \mathrm{sec}\right)
\end{gathered}
$$

All reactors produce tritium from ternary fission and reactions in the coolant and/or neutron poisons. Light-water reactors produce tritium from transmutation in B-10 and the lithium used for 
water chemistry control. Graphite moderated reactors produce tritium due to impurities in the graphite (Wichner and Dyer, 1979). Helium-cooled reactors produce tritium from He-3. Tritium produced from ternary fission in TRISO fuel is well retained in the fuel (General Atomics, 2009; Oh and Kim, 2009). Relative to the amount of tritium produced via transmutation in flibe, the tritium produced due to impurities in graphite and ternary fission is very small, generally not released to the reactor coolant system, and is neglected in this work focusing on FHRs.

The tritium production rate in flibe depends on several factors: neutron spectrum, neutron flux, total salt inventory, core salt inventory, and Li-7 enrichment. Several estimates of tritium production rates in salt-cooled reactors have been made over the years, but only 1 set of experimental measurements have been made. In 1969, during planning for the molten-salt breeder reactor (MSBR), shortly before the MSRE was shut down for the last time, the importance of tritium production and distribution in large salt-cooled reactors was realized (Thoma, 1971). At full power, the MSRE (a molten-salt reactor where the fuel is dissolved in the coolant) produced about 7.3 MWt and the total tritium production rate was $2.0 \times 10^{12} \mathrm{~Bq}$ per day $(54 \mathrm{Ci} / \mathrm{d})(\mathrm{Briggs}, 1971)$. In 2004, it was estimated that a $2400 \mathrm{MWt}$ FHR (known at the time as an Advanced High Temperature Reactor, or AHTR) would produce $1.85 \times 10^{14} \mathrm{~Bq}(5000 \mathrm{Ci})$ of $\mathrm{T}$ per day at the beginning of life and $1.85 \times 10^{13}$ $\mathrm{Bq}(500 \mathrm{Ci})$ of $\mathrm{T}$ per day at equilibrium (Ingersoll et al., 2004). If this estimate is normalized by reactor power, it predicts that an FHR should produce $7.7 \times 10^{13} \mathrm{~Bq}(2083 \mathrm{Ci})$ of tritium/GWd.

Another way to calculate the tritium production rate in an FHR as a function of time is by use of Eq. (6) from (Cisneros, 2013). The first term accounts for tritium production from $\mathrm{Li}-7$, assuming the number density of $\mathrm{Li}-7$ remains constant. The second term accounts for the production of tritium due to transmutation in Li-6 while accounting for Li-6 burnup. The third term accounts for production of Li-6 from transmutation in Be-9 and the subsequent destruction of this Li- 6 by either tritium production or neutron absorption. The symbols in Eq. (6) are defined below. Table 1 shows the flux and cross sections required for calculating tritium production using Eq. (6) for a PB-FHR. From the specifications for the $236 \mathrm{MWt}$ Mk1 PB-FHR, $\mathrm{V}_{\text {core }}=7.2 \mathrm{~m}^{3}$ and $\mathrm{V}_{\text {loop }}=46.82 \mathrm{~m}^{3}$ (Andreades et al., 2014). Using these volumes and the values in Table 1, the tritium production rate can be calculated as a function of reactor operating time (effective full power years, EFPY) normalized by the reactor thermal output, as shown in Fig. 2. Initially, when the flibe coolant is fresh, the tritium production rate is $3.7 \times 10^{14} \mathrm{~Bq} / \mathrm{GWd}(10,000 \mathrm{Ci} / \mathrm{GWd})$. Once the initial $0.005 \mathrm{wt} \%$ Li- 6 has been reduced and the rate of Li- 6 destruction is balanced by the rate of Li- 6 production from $\mathrm{Be}-9$, the tritium production rate is about $1.1 \times 10^{14} \mathrm{~Bq} / \mathrm{GWd}(3000 \mathrm{Ci} / \mathrm{GWd})$ after $15 \mathrm{EFPY}$. Table 2 summarizes the beginning of life (BOL) and equilibrium (EQ) rates of tritium production in a prototypical PB-FHR (excluding tritium produced from ternary fission and impurities in graphite) and compares them with the tritium generation rates in other reactor types.

Among other things, Eq. (6) depends on the ratio of the core coolant volume to the primary system coolant volume. In a PB-FHR, the pebble packing fraction is 0.60 . This means that $40 \%$ of the core volume is occupied by the coolant. In an MSR, the volume of fuel-salt existing in the core is a much smaller fraction of the core volume. In the MSRE, the fuel-salt channels in the graphite 
moderator were small relative to the graphite volume (Haubenreich et al., 1964). It may be possible to reduce the tritium production rate in an FHR by altering the core layout (fuel form, geometry, etc.) in order to have a smaller fraction of salt in the core.

$\dot{\mathrm{T}}(t)=$ tritium production rate at time $t$ of reactor operation (atoms $\mathrm{T} / \mathrm{cm}^{3}-\mathrm{s}$ )

$t=$ cumulative reactor operating time (s)

$\phi=$ energy and volume-averaged neutron flux in the Mk1 PB-FHR core $\left(\mathrm{n} / \mathrm{cm}^{2}-\mathrm{s}\right)$

$\sigma^{\mathrm{T}}{ }_{\mathrm{Li}-7}=$ microscopic cross section for tritium production in Li-7 (barn)

$\mathrm{N}_{\mathrm{Li}-7}=$ number density of Li-7 in flibe at a given temperature (atoms $/ \mathrm{cm}^{3}$ )

$\sigma_{\text {Li-6 }}^{\mathrm{T}}=$ microscopic cross section for tritium production in Li-6 (barn)

$\mathrm{N}_{\mathrm{Li}-7}^{\circ}=$ initial number density of Li-6 in flibe at a given temperature (atoms $/ \mathrm{cm}^{3}$ )

$\mathrm{V}_{\text {core }}=$ volume of flibe in reactor core $\left(\mathrm{m}^{3}\right)$

$\mathrm{V}_{\text {loop }}=$ total volume of flibe in reactor primary system $\left(\mathrm{m}^{3}\right)$

$\sigma_{\text {Li- } 6}^{\text {abs }}=$ microscopic absorption cross section in Li-6 (barn)

$\sigma_{\mathrm{Be}-9}^{\alpha}=$ microscopic cross section for He- 6 production from $\mathrm{n}, \alpha$ reaction in in Be-9 (barn)

$\mathrm{N}_{\mathrm{Be}-9}=$ number density of Be-9 in flibe at a given temperature (atoms $/ \mathrm{cm}^{3}$ )

$$
\dot{T}(t)=\phi \sigma_{L i-7}^{\mathrm{T}} N_{L i-7}+\phi \sigma_{L i-6}^{\mathrm{T}}\left(N_{L i-6}^{o} e^{-\frac{V_{\text {core }}}{V_{\text {loop }}} \phi \sigma_{L i-6}^{a b s} t}+\frac{\phi \sigma_{B e-9}^{\alpha} N_{B e-9}}{\phi \sigma_{L i-6}^{a b s}}\left(1-e^{-\frac{V_{\text {core }}}{V_{\text {loop }}} \phi \sigma_{L i-6}^{a b s} t}\right)\right)
$$

Table 1

PB-FHR energy and volume-averaged flux in the coolant and one-group cross sections. From (Cisneros, 2013).

\begin{tabular}{|l|l|}
\hline$\phi\left(\mathrm{n} / \mathrm{cm}^{2}-\mathrm{s}\right)$ & $3.41 \times 10^{14}$ \\
\hline$\sigma_{\text {Li- } 6}^{\mathrm{T}}(\mathrm{b})$ & 148.026 \\
\hline$\sigma_{\text {Li-6 }-6}^{\mathrm{abs}}(\mathrm{b})$ & 148.032 \\
\hline$\sigma_{\text {Be-9 }}^{\alpha}(\mathrm{b})$ & $3.63 \times 10^{-3}$ \\
\hline$\sigma_{\text {Li-7 }}^{\mathrm{T}}(\mathrm{b})$ & $1.00 \times 10^{-3}$ \\
\hline
\end{tabular}




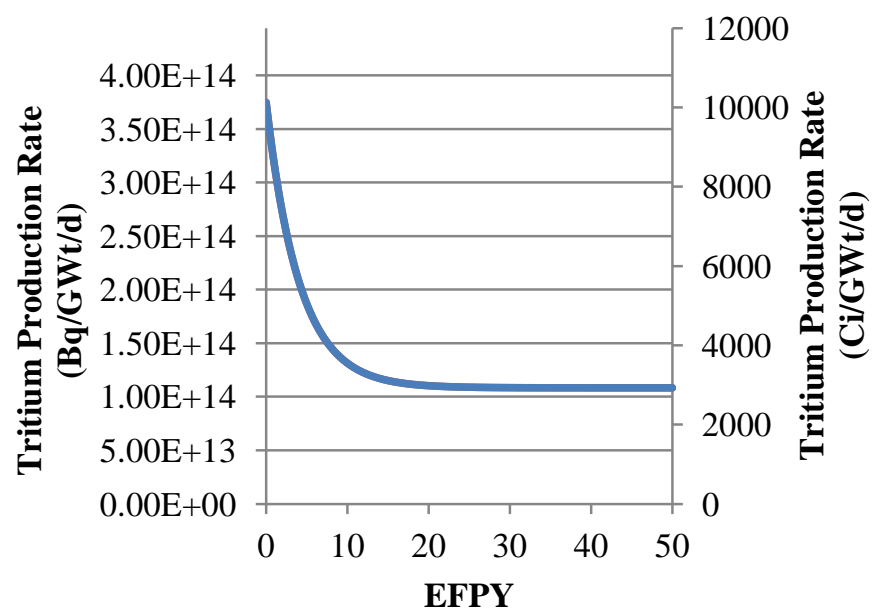

Fig. 2. Tritium production rate for Mk1 PB-FHR using flibe enriched to 99.995 wt\% Li-7.

Table 2

Tritium production rates in different reactors compared to FHRs. FHR values calculated from Eq. (6) and Table 1.

\begin{tabular}{|c|c|c|c|}
\hline \multirow{2}{*}{} & \multicolumn{4}{|c|}{ Tritium Production Rates } \\
\cline { 2 - 5 } & $(\mathrm{Bq} / \mathrm{GWd})$ & $(\mathrm{Ci} / \mathrm{GWd})$ & $(\mathrm{g} / \mathrm{GWd})$ \\
\hline BWR* & $4.6 \mathrm{E}+11$ & 12.3 & $1.27 \mathrm{E}-3$ \\
\hline PWR* & $5.1 \mathrm{E}+11$ & 13.9 & $1.43 \mathrm{E}-3$ \\
\hline HTGR $^{*}$ & $6.8 \mathrm{E}+11$ & 18.5 & $1.91 \mathrm{E}-3$ \\
\hline Fast Reactor* & $9.2 \mathrm{E}+11$ & 24.9 & $2.57 \mathrm{E}-3$ \\
\hline Heavy Water Reactor $*$ & $4.4 \mathrm{E}+13$ & 1176 & 0.12 \\
\hline FHR & $\begin{array}{c}\text { BOL: 3.7E+14 } \\
\text { EQ: } 1.1 \mathrm{E}+14\end{array}$ & $\begin{array}{c}\text { BOL: } 10129 \\
\text { EQ: } 2931\end{array}$ & $\begin{array}{c}\text { BOL: } 1.04 \\
\text { EQ: } 0.30\end{array}$ \\
\hline
\end{tabular}

*Value calculated from data in (Management of Waste Containing Tritium and Carbon-14, 2004).

\section{Definition of redox potential and relationship to tritium behavior and corrosion phenomena}

Tritium is an important issue for FHRs for two reasons. First, tritium is a corrosion concern. As Eq. (1) and Eq. (2) show, tritium is produced in flibe as tritium fluoride (Anderl et al., 2004; Calderoni et al., 2009; Fukada et al., 2006; Suzuki et al., 1998). TF is chemically oxidizing toward structural metals and represents the principle oxidative species and corrosion concern in FHRs. If TF undergoes a chemical reaction, it can be converted to $\mathrm{T}_{2(\mathrm{~g})}$. This type of reaction occurs when $\mathrm{TF}$ oxidizes metal or if it is reduced to $\mathrm{T}_{2}$ by any redox control methods used in the FHR coolant. Second, tritium is a radiological concern. Tritium in the form of $\mathrm{T}_{2}$ can readily diffuse through and escape from most structural metals at FHR temperatures $\left(\sim 700^{\circ} \mathrm{C}\right)$ (Shapiro and Reed, 1970; Suzuki et al., 2000). Since the FHR will operate with an open-air Brayton power cycle, tritium diffusion from the salt through the heat-exchanger and into the air must be strictly limited.

The term "chemical redox potential" is used to describe whether the coolant is oxidizing or reducing with respect to structural metals (e.g. $\mathrm{Cr}, \mathrm{Fe}, \mathrm{Mo}, \mathrm{Ni}$, etc.). It is a useful quantity for discussing both tritium behavior and corrosion reactions. In a clean (un-fueled) fluoride salt reactor 
coolant, tritium behavior and corrosion are coupled phenomena which can be described in reference to the redox potential. "Redox" refers to a reaction where one reactive species is reduced ("red") and the other is oxidized ("ox"). For example, Eq. (7) shows a reaction where dissolved tritium fluoride (TF) oxidizes metallic $\mathrm{Cr}$ to $\mathrm{CrF}_{2}$, which then dissolves in the coolant as $\mathrm{Cr}^{2+}$ and $2 \mathrm{~F}^{-}$. In this case, tritium ( $\mathrm{T}$ ) is reduced and $\mathrm{Cr}$ is oxidized. "Potential" describes the thermodynamic propensity for this reaction to occur and dictates the ratios of $\mathrm{Cr}^{2+}: \mathrm{Cr}$ and $\mathrm{T}^{+}: \mathrm{T}_{2}$ which would exist in the salt at equilibrium.

$$
2 \mathrm{TF}_{(d)}+\mathrm{Cr}_{(s)} \rightarrow \mathrm{CrF}_{2(d)}+\mathrm{T}_{2(g)}
$$

A good way to visualize the relative stability of salt constituents and structural metals is with an Ellingham diagram which plots the Gibbs free energy of formation as a function of temperature for various fluorides of interest. The more negative the Gibbs free energy of formation, the more stable that compound will be. Fig. 3 shows an Ellingham diagram for fluorides of structural metals and the constituents of flibe. Fig. 3 was constructed by calculating the Gibbs formation free energies from empirical relations compiled by Baes (Baes Jr., 1969).

Fig. 3 shows that $\mathrm{LiF}$ and $\mathrm{BeF}_{2}$ have two of the most negative formation free energies, making them two of the most stable fluorides. Fluorides of major structural metals $(\mathrm{Cr}, \mathrm{Ni}$, and $\mathrm{Fe})$ have formation free energies more positive than $\mathrm{LiF}$ and $\mathrm{BeF}_{2}$. This means that in pure flibe, structural metal fluorides will not form, and metallic $\mathrm{Cr}$, Ni, and Fe will be stable. Fig. 3 shows that HF (which is produced in the form of tritium fluoride in the FHR) has a Gibbs formation free energy more positive than that of the fluorides of structural metals. This means that HF can corrode structural metals and could pose a significant corrosion problem (Cantor and Grimes, 1974). Of the structural metals, $\mathrm{Cr}$ forms the most stable metal fluoride. Thus most corrosion in the FHR will be through selective oxidation of $\mathrm{Cr}$, and the long-term rate of corrosion is dictated by the rate of solid-state $\mathrm{Cr}$ diffusion to the metal-salt interface (Evans III et al., 1961; Ignatiev and Surenkov, 2012; Koger, 1972a; Williams et al., 2006). Eq. (7) shows that TF (or HF) will oxidize $\mathrm{Cr}$ to $\mathrm{CrF}_{2}$, and a byproduct of this reaction is $\mathrm{T}_{2(\mathrm{~g})}$ which is highly mobile through heat exchanger (HX) materials. 


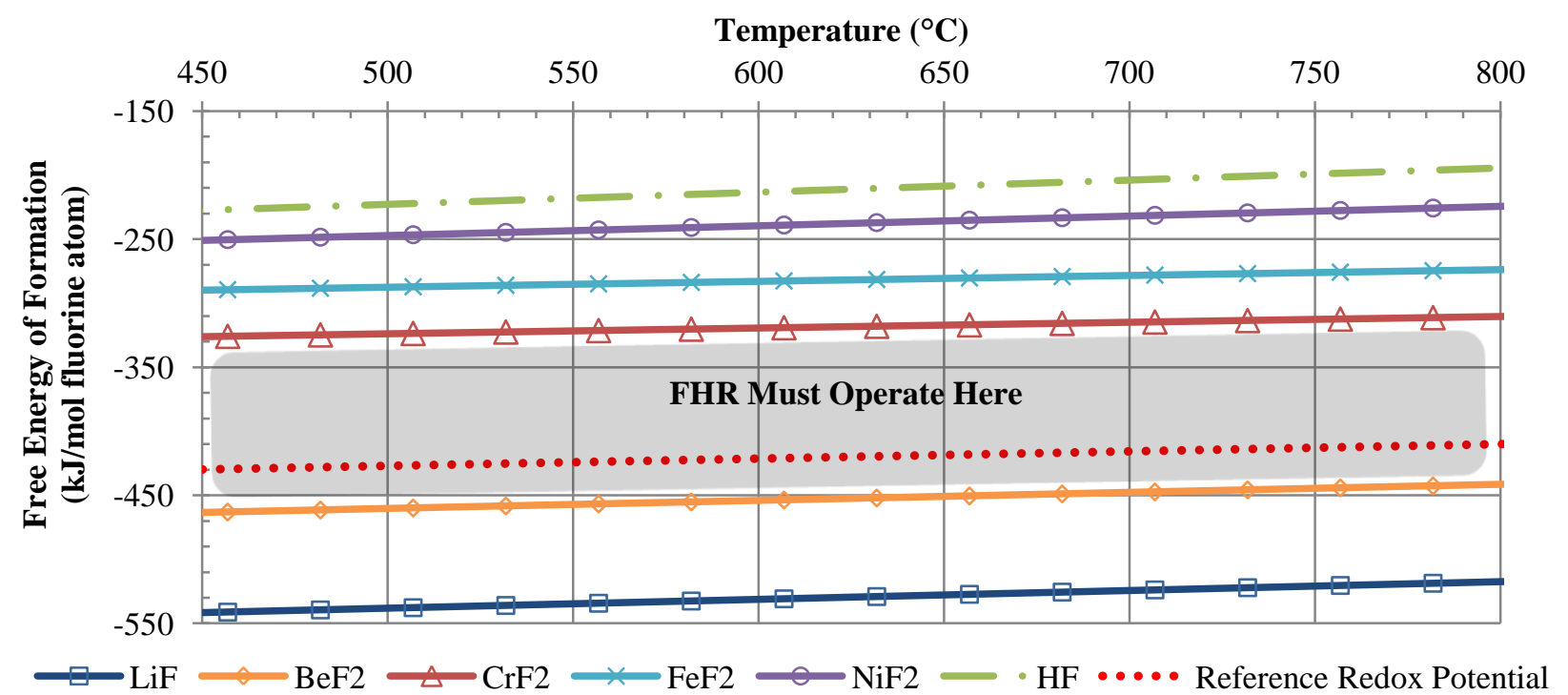

Fig. 3. Ellingham diagram comparing relative stabilities of fluorides.

In fluoride salt-cooled reactors, corrosion products are metal fluorides (such as $\mathrm{CrF}_{2}$ ). Metal fluorides are soluble in fluoride salts. Thus, protecting metals in the FHR by passivation on the metal surface is not possible. The best means to protect the metal in an FHR is to keep the salt clean from impurities and/or impose a chemically reducing condition on the salt. A redox potential which maintains the stability of the coolant and the structural metals is required. The shaded region highlighted in Fig. 3 indicates the potential (in terms of a Gibbs free energy of formation) that must exist in flibe for both the salt and structural metals to be chemically stable. The MSRE used a ratio of dissolved $\mathrm{UF}_{4}: \mathrm{UF}_{3}$ of 100:1 in order to impose a satisfactory redox potential in the coolant (Beneš and Konings, 2012; Haubenreich and Engel, 1970). Here, this potential was calculated in terms of a Gibbs formation free energy using the Gibbs-Duhem relationship and is plotted in Fig. 3 as the dotted line labeled "Reference Redox Potential". Any fluoride that exists above the dotted line for the reference potential will not be a stable fluoride, and any fluoride that exists below the dotted line will be a stable fluoride. Since both the FHR and MSRE have a fluoride salt in contact with graphite and metal containing chromium, the chemical redox potential in the MSRE can serve as a suitable baseline reference redox potential for the FHR. The FHR uses a clean, unfueled salt which means that $\mathrm{UF}_{4} / \mathrm{UF}_{3}$ cannot be used to control the redox potential in the FHR; however, other options could be employed in order to attain the same or similar potential. For example, redox buffers based on metal fluorides which exist in two oxidation states could be dissolved in flibe (e.g. $\mathrm{CeF}_{4} / \mathrm{CeF}_{3}$, $\mathrm{SmF}_{3} / \mathrm{SmF}_{2}, \mathrm{YbF}_{3} / \mathrm{YbF}_{2}, \mathrm{VF}_{3} / \mathrm{VF}_{2}$, and $\mathrm{EuF}_{3} / \mathrm{EuF}_{2}$ ) or a gaseous mixture of $\mathrm{HF} / \mathrm{H}_{2}$ could be used to apply a redox potential to the salt (Del Cul et al., 2002; Toth et al., 1995). Other options include the use of a sacrificial anode (which will react with tritium fluoride to produce $\mathrm{T}_{2}$ ) such as $\mathrm{Be}(\mathrm{Calderoni}$ et al., 2009) or $\mathrm{Al}$ (Stempien, 2015).

Besides expressing the redox potential in terms of a Gibbs free energy of formation, another useful convention is to refer to the redox potential in the FHR coolant as defined by the "fluorine 
potential" suggested by (Olander, 2002). In the FHR, TF is generated in the salt due to neutron transmutation and $\mathrm{T}_{2}$ is produced due to metal corrosion by $\mathrm{TF}$. Additionally, $\mathrm{HF} / \mathrm{H}_{2}$ might be deliberately added for redox control. In either case, the relative equilibrium amounts of $\mathrm{TF}$ and $\mathrm{T}_{2}$ (or $\mathrm{HF}$ and $\mathrm{H}_{2}$ ) in the FHR coolant can be related to the fluorine potential $\left(\Delta \mathrm{G}_{\mathrm{F} 2}\right)$ in the salt. If $\mathrm{HF}$ and $\mathrm{H}_{2}$ are used to actively control the redox potential, then the fluorine potential will be dictated by the ratio of $\mathrm{HF}: \mathrm{H}_{2}$ injected into the system. Alternatively, if some other means of applying redox control is assumed (such as impressed current or a dissolved redox buffer), this will enforce a particular fluorine (redox) potential on the coolant, and this redox potential will determine the relative amounts of $\mathrm{TF}$ and $\mathrm{T}_{2}$ in the system. Thus, depending on the specific arrangement of the system, a specific $\Delta \mathrm{G}_{\mathrm{F} 2}$ could be enforced (and from this fluorine potential, the ratio of TF: $\mathrm{T}_{2}$ could be calculated); or one could specify a particular TF: $\mathrm{T}_{2}$ (and from this, calculate the corresponding $\left.\Delta \mathrm{G}_{\mathrm{F} 2}\right)$.

Eq. (8) gives the fluorine potential $\left(\Delta \mathrm{G}_{\mathrm{F} 2}\right)$ in flibe as a function of temperature ( $\mathrm{T}$ in units of $\mathrm{K}$ ) and the relative amounts of $\mathrm{TF}$ and $\mathrm{T}_{2}$ present in the salt (Olander, 2002). Given by Eq. (9) and Eq. (10), $\mathrm{P}_{\mathrm{TF}}$ and $\mathrm{P}_{\mathrm{T} 2}$ are the partial pressures of $\mathrm{TF}\left(p_{\mathrm{TF}}\right)$ and $\mathrm{T}_{2}\left(p_{\mathrm{T} 2}\right)$ divided by the total pressure $p_{\text {total }}$. $\mathrm{R}$ is the universal gas constant $(\mathrm{kJ} / \mathrm{mol}-\mathrm{K})$, and $\Delta \mathrm{G}_{\mathrm{TF}}^{\mathrm{o}}$ is the Gibbs formation free energy for TF. A thermodynamics program called HSC Chemistry v.7.1 was used to calculate $\Delta \mathrm{G}_{\mathrm{TF}}^{\mathrm{o}}$ from a vast database of reaction enthalpies and entropies with respect to temperature for use with Eq. (8). Using Eq. (8), the ratio $\left[\mathrm{P}_{\mathrm{TF}}\right]^{2}:\left[\mathrm{P}_{\mathrm{T} 2}\right]$ is plotted in Fig. 4 as a function of the fluorine potential $\left(\Delta \mathrm{G}_{\mathrm{F} 2}\right)$ for a temperature of $650{ }^{\circ} \mathrm{C}$. The chemical redox potential in the coolant determines the relative amounts of tritium existing as TF or $\mathrm{T}_{2}$ in the salt. A more oxidizing potential results in the amount of tritium existing as TF increasing relative to the amount of $\mathrm{T}_{2}$. In Fig. 3, the redox potential used in the MSRE was chosen as the reference potential for the FHR, and this redox potential is plotted in terms of the Gibbs formation free energy. Converting this into an equivalent fluorine potential gives a fluorine redox potential of $-700.5 \mathrm{~kJ} / \mathrm{mol} \mathrm{F}_{2}$ which translates into a fraction $\left[P_{\mathrm{TF}}\right]^{2} /\left[P_{\mathrm{T} 2}\right]$ of $8.45 \times 10^{-9}$ at $650{ }^{\circ} \mathrm{C}$.

$$
\begin{gathered}
\Delta \mathrm{G}_{\mathrm{F}_{2}}=2 \mathrm{RT} \ln \left(\frac{\mathrm{P}_{\mathrm{TF}}}{\sqrt{\mathrm{P}_{\mathrm{T}_{2}}}}\right)+2 \Delta \mathrm{G}_{\mathrm{TF}}^{\mathrm{o}} \\
\mathrm{P}_{T F}=\frac{p_{T F}}{p_{\text {total }}} \\
\mathrm{P}_{T_{2}}=\frac{p_{T_{2}}}{p_{\text {total }}}
\end{gathered}
$$




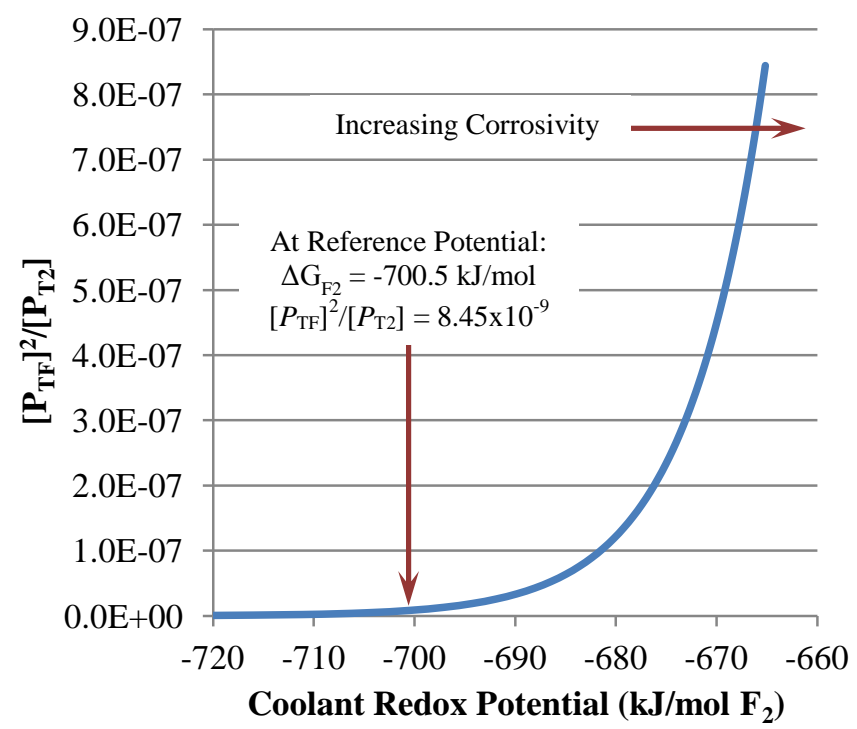

Fig. 4. Relative amounts of $\mathrm{TF}$ and $\mathrm{T}_{2}$ in the salt as a function of the salt fluorine potential.

Next, a means for determining the absolute values for $\mathrm{P}_{\mathrm{TF}}$ and $\mathrm{P}_{\mathrm{T} 2}$ from the ratio $\mathrm{P}_{\mathrm{TF}} /\left(\mathrm{P}_{\mathrm{T} 2}\right)^{1 / 2}$ is derived. The literature consensus is that the solubility of $\mathrm{TF}$ and $\mathrm{T}_{2}$ in fluoride salts is according to Henry's law (Calderoni et al., 2008; Field and Shaffer, 1967; Fukada et al., 2005; Fukada and Morisaki, 2006; Malinauskas and Richardson, 1974). Henry's law, expressed in Eq. (11), states that the concentration $c$ of a gas in a liquid solution is proportional to the product of the partial pressure $p$ of that gas over the solution with the Henry's law constant $k_{\text {Henry }}$ at a given temperature. The Henry's law constant $\left(k_{\mathrm{HF}}\right)$ from Field and Shaffer (Field and Shaffer, 1967) was converted to units of [mol $\mathrm{HF} / \mathrm{m}^{3}$ flibe-Pa] using the molar mass $(32.89 \mathrm{~g} / \mathrm{mol})$ and density of flibe reported by (Sohal et al., 2010). An exponential fit was applied to these data points in order to yield Eq. (12). The Ostwald constant for the solubility of $\mathrm{H}_{2}$ in flibe from (Malinauskas and Richardson, 1974) was converted to a Henry's law constant in units of $\left[\mathrm{mol} \mathrm{H}_{2} / \mathrm{m}^{3}\right.$ flibe-Pa]. An exponential best-fit for these data produced the expression in Eq. (13). In both Eq. (12) and Eq. (13), $k_{\text {Henry }}$ has units of $\mathrm{mol} / \mathrm{m}^{3} \mathrm{flibe}-\mathrm{Pa}$ and $T$ is in degrees Celsius $\left({ }^{\circ} \mathrm{C}\right)$. Here, it is assumed that the solubility of $\mathrm{T}_{2}$ and $\mathrm{TF}$ in flibe should be roughly the same as that for $\mathrm{H}_{2}$ and $\mathrm{HF}$.

$$
\begin{gathered}
c=p \times k_{\text {Henry }} \\
k_{\text {Henry }, \mathrm{HF}}=1.707 \times 10^{-3} e^{-4.260 \times 10^{-3} T} \\
k_{\text {Henry, } \mathrm{H}_{2}}=2.714 \times 10^{-8} e^{4.235 \times 10^{-3} T}
\end{gathered}
$$

Henry's law and a mass balance for the total amount of tritium in the salt are employed in order to arrive at a set of two equations and two unknowns. First, Henry's law is written for TF and $\mathrm{T}_{2}$ as Eq. (14) and Eq. (15), respectively. Here, $c_{\mathrm{TF}}$ and $c_{\mathrm{T} 2}$ are the concentrations of $\mathrm{TF}$ and $\mathrm{T}_{2}$ in flibe in units of $\mathrm{mol} / \mathrm{m}^{3}$ flibe. The partial pressures of $\mathrm{TF}$ and $\mathrm{T}_{2}$ are written as $p_{\mathrm{TF}}$ and $p_{\mathrm{T} 2}$ in units of $\mathrm{Pa}$. Eqs. (9) and (10) are solved for $p_{\mathrm{TF}}$ and $p_{\mathrm{T} 2}$ and then substituted into Eqs. (14) and (15) in order to give Eqs. (16) and (17). Solving Eqs. (16) and (17) for $\mathrm{P}_{\mathrm{TF}}$ and $\mathrm{P}_{\mathrm{T} 2}$, substituting these into Eq. (8), 
and rearranging the equation, results in Eq. (18). In a given volume of flibe, the total amount of tritium in that volume of flibe can be expressed by summing the two chemical forms of tritium according to Eq. (19). Solving Eq (19) for $c_{\mathrm{TF}}$ and substituting this into Eq. (18) gives Eq. (20).

Eq (20) can be used in several different ways. If the total system pressure is known, then $p_{\text {total }}$ is known. In the case of the FHR, the total system pressure is $1 \mathrm{~atm}$ or $101325 \mathrm{~Pa}$. If the redox potential in terms of the fluorine potential $\left(\mathrm{kJ} / \mathrm{mol}-\mathrm{F}_{2}\right)$ of the salt is known, then $\Delta \mathrm{G}_{\mathrm{F} 2}$ is known. The Henry's law constants for TF and $\mathrm{T}_{2}$ are known from Eqs. (12) and (13). If $\mathrm{c}_{\text {total }}$ is also known, then Eq. (20) can be solved for $c_{\mathrm{T} 2}$. Once both $c_{\text {total }}$ and $c_{\mathrm{T} 2}$ are known, $c_{\mathrm{TF}}$ can be calculated using Eq (19). Alternatively, if the right-hand side of $\mathrm{Eq}(20)$ is known, $\mathrm{P}_{\mathrm{TF}} /\left(\mathrm{P}_{\mathrm{T} 2}\right)^{0.5}$ can be solved for. As another option, if the relative amounts of $\mathrm{TF}$ and $\mathrm{T}_{2}$ in the system are known (i.e. $\mathrm{P}_{\mathrm{TF}} /\left(\mathrm{P}_{\mathrm{T} 2}\right)^{0.5}$ is known) Eq. (20) can be solved for the redox (fluorine) potential $\left(\Delta \mathrm{G}_{\mathrm{F} 2}\right)$ in the coolant.

$$
\begin{gathered}
c_{\mathrm{TF}}=k_{\mathrm{Henry}, \mathrm{TF}} p_{\mathrm{TF}} \\
c_{\mathrm{T}_{2}}=k_{\mathrm{Henry}, \mathrm{T}_{2}} p_{\mathrm{T}_{2}} \\
c_{\mathrm{TF}}=k_{\mathrm{Henry}, \mathrm{TF}} P_{\mathrm{TF}} p_{\text {total }} \\
c_{\mathrm{T}_{2}}=k_{\mathrm{Henry}, \mathrm{T}_{2}} P_{\mathrm{T}_{2}} p_{\text {total }} \\
\frac{\mathrm{P}_{\mathrm{TF}}}{\sqrt{\mathrm{P}_{\mathrm{T}_{2}}}}=\frac{c_{\mathrm{TF}} / k_{\mathrm{Henry}, \mathrm{TF}} p_{\text {total }}}{\sqrt{c_{\mathrm{T}_{2}} / k_{\mathrm{Henry}, \mathrm{T}_{2}} p_{\text {total }}}}=\exp \left(\frac{\Delta \mathrm{G}_{\mathrm{F}_{2}}-2 \Delta \mathrm{G}_{\mathrm{TF}}^{\mathrm{o}}}{2 \mathrm{RT}}\right) \\
\left.\frac{c_{\text {total }}=2 c_{\mathrm{T}_{2}}}{\mathrm{P}_{\mathrm{TF}}}=\frac{c_{\mathrm{TF}}}{\sqrt{\mathrm{P}_{\mathrm{T}_{2}}}}=\frac{\Delta \mathrm{G}_{\mathrm{F}_{2}}-2 \Delta \mathrm{G}_{\mathrm{TF}}^{\mathrm{o}}}{2 \mathrm{RT}}\right) \\
\left.\sqrt{c_{\mathrm{T}_{2}} / k_{\mathrm{Henry}, \mathrm{T}_{2}} p_{\text {total }}}\right)
\end{gathered}
$$

The chemical redox potential in the coolant dictates the relative amounts of $\mathrm{TF}$ and $\mathrm{T}_{2}$, and hence, also determines the extent of corrosion. The equilibrium concentration of $\mathrm{CrF}_{2}$ dissolved in flibe can be calculated as a function of the Cr concentration in the alloy in contact with flibe, the temperature, and the redox potential in the salt. A more oxidizing potential results in the amount of tritium existing as TF increasing relative to the amount of $\mathrm{T}_{2}$. This also results in an increase in the equilibrium concentration of $\mathrm{Cr}^{2+}$ corrosion products in the salt. To begin with, the corrosion reaction is written as Eq. (21), and the equilibrium constant for this reaction is written as Eq. (22). Here, $\left[\mathrm{CrF}_{2}\right]$ is the equilibrium concentration of $\mathrm{CrF}_{2}$ in flibe (as a mole fraction) contacting a given alloy, and $\left[\mathrm{Cr}_{(\text {s.s. }}\right]$ is the concentration of $\mathrm{Cr}$ in that alloy (as a mole fraction). Here, $P_{\mathrm{TF}}$ and $P_{\mathrm{T} 2}$ are the partial pressures of TF $\left(p_{\mathrm{TF}}\right)$ and $\mathrm{H}_{2}\left(p_{\mathrm{T} 2}\right)$ divided by the total pressure $p_{\text {total }}$. Eq. (23) provides an empirical relationship for this equilibrium constant (Baes Jr., 1969). Plugging Eq. (22) into Eq. (23) and solving for $\left[\mathrm{CrF}_{2}\right]$ gives Eq. (24). Note that Eq. (24) includes the fraction $\left[P_{\mathrm{TF}}\right]^{2} /\left[P_{\mathrm{T} 2}\right]$. The 
value of the fraction $\left[P_{\mathrm{TF}}\right]^{2} /\left[P_{\mathrm{T} 2}\right]$ is related to the chemical (fluorine) redox potential in the salt as defined in Eq. (8) and shown in Fig. 4. The redox potential maintained in the MSRE was set by a ratio of $\mathrm{UF}_{4}$ to $\mathrm{UF}_{3}$ of 100:1. This ratio, expressed as an equivalent fluorine potential, gives a fluorine redox potential of $-700.5 \mathrm{~kJ} / \mathrm{mol} \mathrm{F}_{2}$ which translates into a fraction $\left[P_{\mathrm{TF}}\right]^{2} /\left[P_{\mathrm{T} 2}\right]$ of $8.45 \times 10^{-9}$ at $650{ }^{\circ} \mathrm{C}$. This potential will serve as a reference point for the FHR, and could be maintained in the coolant by purging the salt with gas mixture of $\left[P_{\mathrm{HF}}\right]^{2} /\left[P_{\mathrm{H} 2}\right]$ of $8.45 \times 10^{-9}$ or by other redox control methods mentioned earlier.

Fig. 5 shows the equilibrium concentration of $\mathrm{Cr}^{2+}$ dissolved in flibe contacting Type $316 \mathrm{~L}$ stainless steel at $650{ }^{\circ} \mathrm{C}$. The bottom horizontal axis shows the fluorine potential, and the top horizontal axis shows the corresponding ratio of $\left[\mathrm{P}_{\mathrm{HF}}\right]^{2}:\left[\mathrm{P}_{\mathrm{H} 2}\right]$. As the fraction of TF increases, the redox fluorine potential increases, the salt becomes more oxidizing, and a greater amount of $\mathrm{Cr}^{2+}$ is dissolved in the salt. The calculation from Eq. (24) does not account for the effects of the solubility limit, and predicts that at high fluorine potentials, the calculated equilibrium concentration of $\mathrm{Cr}^{2+}$ can exceed the solubility. This is impossible, and the solubility limit will enforce precipitation of $\mathrm{CrF}_{2}$ corrosion products, if necessary. Another significant factor is that the reaction in Eq. (21) has a negative reaction enthalpy, meaning it is exothermic. Since heat is evolved from the reaction in Eq. (21), the reaction proceeds more strongly to the right at lower temperatures. This is also evident in the temperature dependence of the equilibrium constant in Eq. (23). This implies that in a system, such as the FHR, where TF is the principle oxidant, mass transfer could occur from an area of low temperature to an area of high temperature. This possibility was first acknowledged by Evans et. al. (Evans III et al., 1971).

$$
\begin{gathered}
C r_{\text {(s.s.) }}+2 T F \square \quad C r F_{2(d)}+T_{2(g)} \\
\mathrm{K}=\frac{\left[\mathrm{CrF}_{2}\right]\left[P_{T_{2}}\right]}{\left[\mathrm{Cr}_{(\text {s.s. }}\right]\left[P_{\mathrm{TF}}\right]^{2}} \\
\log (\mathrm{K})=-5.12+\frac{9060}{T} \\
{\left[\mathrm{CrF}_{2}\right]=10^{\wedge}\left\{-5.12+\frac{9060}{T}+\log \left(\left[\mathrm{Cr}_{\text {(s.s.) }}\right]\right)+\log \left(\frac{\left[P_{T F}\right]^{2}}{\left[P_{T_{2}}\right]}\right)\right\}}
\end{gathered}
$$




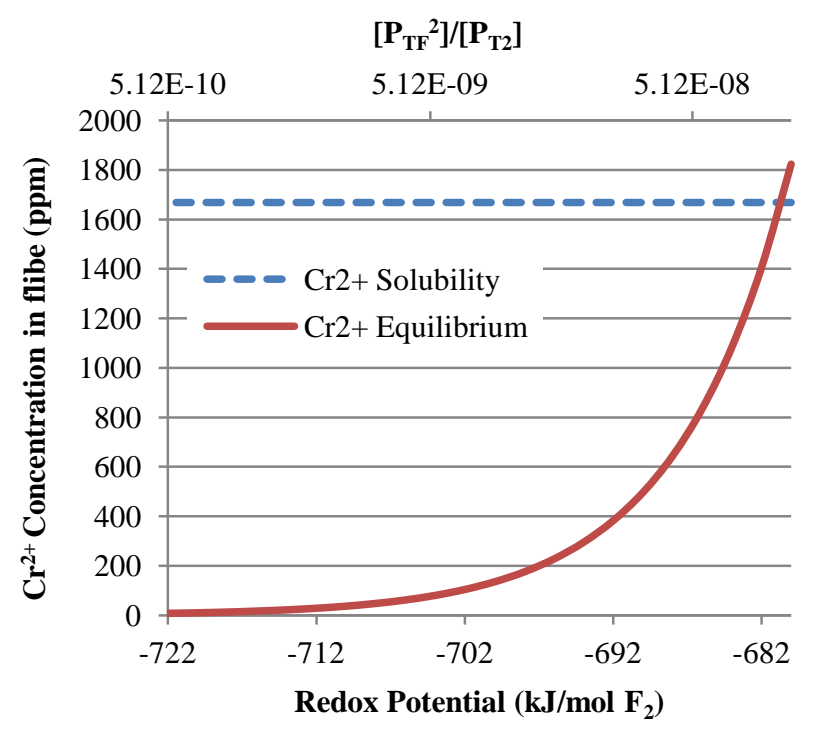

Fig. 5. Equilibrium concentration of $\mathrm{Cr}^{2+}$ in flibe calculated with Eq. (24). Solubility limit from (Sohal et al., 2010).

In MSRs (where the fuel is dissolved in the coolant), the higher-valence states of dissolved actinides (namely $\mathrm{UF}_{4}$ ) are the principle oxidants. Thermodynamically, $\mathrm{UF}_{4}$ is a weaker oxidant than TF; however, the concentration of $\mathrm{UF}_{4}$ in the fuel-salt of an MSR is much higher than that of TF. For MSRs, the reaction of concern is given by Eq. (25). Here the subscript $d$ denotes a species dissolved in the salt, and the subscript s.s. denotes that the $\mathrm{Cr}$ is in a solid solution in an alloy and not in pure, metallic form. Eq. (26) was derived in order to determine the equilibrium concentration of $\mathrm{CrF}_{2}$ dissolved in the salt as a function of temperature and the ratio of $\mathrm{UF}_{4}: \mathrm{UF}_{3}$ in the salt (Stempien, 2015). This relationship will be used in benchmarking the TRIDENT corrosion model in Section 6.2. Unlike the reaction in Eq. (21), the reaction in Eq. (25) has a positive reaction enthalpy, meaning it is endothermic. In systems (such as MSRs) where $\mathrm{UF}_{4}$ is the primary oxidant, this results in mass transfer from the hot section of a loop to the cold section of a loop.

In both an MSR and an FHR, the corrosion rate is limited by the rate of solid-state chromium diffusion from the metal to the metal-salt interface - a phenomena that is strongly temperature dependent. Since the reaction enthalpy for the reaction in Eq. (21) is negative, this reaction is expected to be more favorable at lower temperatures, where the solid-state diffusion of $\mathrm{Cr}$ is slower. Conversely, the reaction in Eq. (25) has a positive reaction enthalpy, and should be more favorable at higher temperatures where the solid-state diffusion of $\mathrm{Cr}$ is faster. Consequently, we expect corrosion in the FHR to be slower than in a MSR.

$$
\begin{gathered}
\mathrm{Cr}_{(\text {s.s. })}+2 \mathrm{UF}_{4(d)} \square \mathrm{CrF}_{2(d)}+2 \mathrm{UF}_{3(d)} \\
{\left[\mathrm{CrF}_{2}\right]=10^{\wedge}\left\{3.02-9600 / T+\log \left(\left[\mathrm{Cr}_{(\text {s.s. }}\right]\right)+2 \log \left(\left[\mathrm{UF}_{4}\right] /\left[\mathrm{UF}_{3}\right]\right)\right\}}
\end{gathered}
$$




\section{Tritium transport}

After tritium is generated in flibe from neutron transmutation, it can be carried along in the reactor coolant which may transport the tritium to different surfaces in the reactor (moderator graphite, fuel pebbles, pipes, heat exchangers, etc.). Different reactions of tritium (corrosion, adsorption, permeation, etc.) may occur at these surfaces and these reactions have interrelated effects.

\subsection{Importance of graphite}

Near the close of MSRE operations, it was found that the moderator graphite was a significant sink for tritium (Briggs, 1971). Since the FHR uses pebble bed fuel, the graphite surface area per unit reactor power in the FHR will be larger than that in the MSRE, and the effect of tritium sorption on graphite will be important for determining tritium transport. Measurements and observations from the MSRE indicate both TF and $\mathrm{T}_{2}$ are adsorbed on graphite (Briggs, 1971; Briggs and Nestor, 1975; Thoma, 1971).

A comprehensive review of the behavior of hydrogen on graphite was performed (Stempien, 2015). The importance of obtaining data about the solubility of hydrogen in materials, permeability of hydrogen in metals, the capacity of graphite for hydrogen, and the reaction rates of hydrogen fluoride dissolved in salt with metals was recognized in a 1974 report (McNeese, 1974), but it would seem that the MSBR program (which came after the MSRE) was terminated (in 1976) before the data could be obtained (MacPherson, 1985). Thus, most of the available data for hydrogen behavior on graphite come from more recent work completed by a variety of researchers. Generally speaking, the higher the Brunauer-Emmett-Teller (BET) surface of a material (also known as specific surface area), the higher the specific hydrogen capacity (atoms $/ \mathrm{cm}^{2}$ or atoms/g) (Wang et al., 2011). A direct, linear dependence of specific hydrogen capacity with specific surface area has been observed (Causey et al., 2012; Wang et al., 2011). It has been found that the solubility of hydrogen in graphite can be related to the temperature and the square root of the pressure of the hydrogen over the graphite (Atsumi et al., 1988). The model developed here considers the adsorption of both TF and $\mathrm{T}_{2}$ on graphite in the core depending on the calculated mass transport parameters and the graphite capacity for tritium (Stempien, 2015).

\subsection{Modeling tritium permeation}

Tritium reaching the surface of a metal membrane may permeate through the membrane from the side of high concentration to the side of low concentration. Tritium in the form of TF does not diffuse through metals (Suzuki et al., 2000). Thus, only $\mathrm{T}_{2}$ is allowed to diffuse out of the primary system through the heat exchangers. The rate at which tritium reaches the metal surface and the relevant solubility laws applicable to the coolant and the metal on the upstream surface provide boundary conditions. Within the metal, the rate of tritium diffusion must be modeled and the amount of tritium conserved. The diffusion of $\mathrm{T}_{2}$ through the heat exchangers is treated as $1 \mathrm{D}$ diffusion 
through the metal tube wall. Only radial diffusion through the metal is considered. Axial diffusion within the metal is neglected. The tube wall is treated as a planar geometry, but the variation in the cross-sectional area of the tube perpendicular to the radial direction is accounted for. On the downstream surface of the metal, the rate of tritium transport from the surface and the prevailing solubility laws provide boundary conditions similar to those on the upstream surface.

Experiments have determined that the permeation rate is limited by mass transport/diffusion and not by the rate of $\mathrm{T}_{2}$ dissociation/recombination on the metal surface (Fukada et al., 2002, 2006). Thus, the assumption adopted here is that the permeation rate is limited by mass transport/diffusion and not by the rate of $\mathrm{T}_{2}$ dissociation/recombination on the metal surface. A detailed set of tritium mass transfer and tritium mass balance equations were developed for the complete FHR system (Stempien, 2015). This section focuses on the boundary conditions developed for determining tritium transport from the reactor coolant into and through the heat exchanger tube walls.

Because the buildup and transport of tritium in the FHR is a transient problem, the numerical value of these boundary conditions changes with each axial segment $\left(\mathrm{N}_{\mathrm{HX}}\right)$ along the $\mathrm{HX}$ and each time step $(i)$ until equilibrium is achieved. The following two assumptions were adopted from (Fukada et al., 2002). First, it is assumed that tritium dissociation/recombination processes at the metal surface are instantaneous. Second, it is assumed that the tritium concentration at the metal side of the coolant-metal interface attains an instant equilibrium with the coolant side of the interface. Fig. 6 illustrates the concentration profile of $\mathrm{T}_{2}$ at the interface between the primary coolant and the heat exchanger metal. Note that in non-porous membranes (such as the metal tube wall) the solute concentration does not have to be continuous (Seader et al., 2010). Using the concentration of $\mathrm{T}_{2}$ in

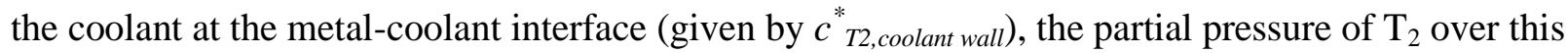
solution $\left(p_{T 2, \text { coolant }}\right)$ is calculated from Henry's law according to Eq. (27). Using the concentration of $\mathrm{T}_{2}$ in the heat exchanger metal at the metal-coolant interface (given by $c^{*}{ }^{*}$,metal wall), the partial pressure of $\mathrm{T}_{2}$ over that metal surface $\left(p_{T 2, \text { metal }}\right)$ is calculated according to Sieverts' law in Eq. (28). Here, the Sieverts' law constant is given by $K_{S, T 2 \text {,metal }}$ in units of $\mathrm{mol} / \mathrm{m}^{3}-\mathrm{Pa}^{2}$. Tables of hydrogen diffusivity, solubility, and permeability in different metals are available in the open literature (Causey et al., 2012; Katsuta and Furukawa, 1981; Kishimoto et al., 1985; Tanabe et al., 1984). The boundary condition specified here requires that these partial pressures $\left(p_{T 2, \text { coolant }}\right.$ and $p_{T 2, m e t a l}$ from Eq. (27) and Eq. (28), respectively) be equal to each other at the coolant-metal interface. 


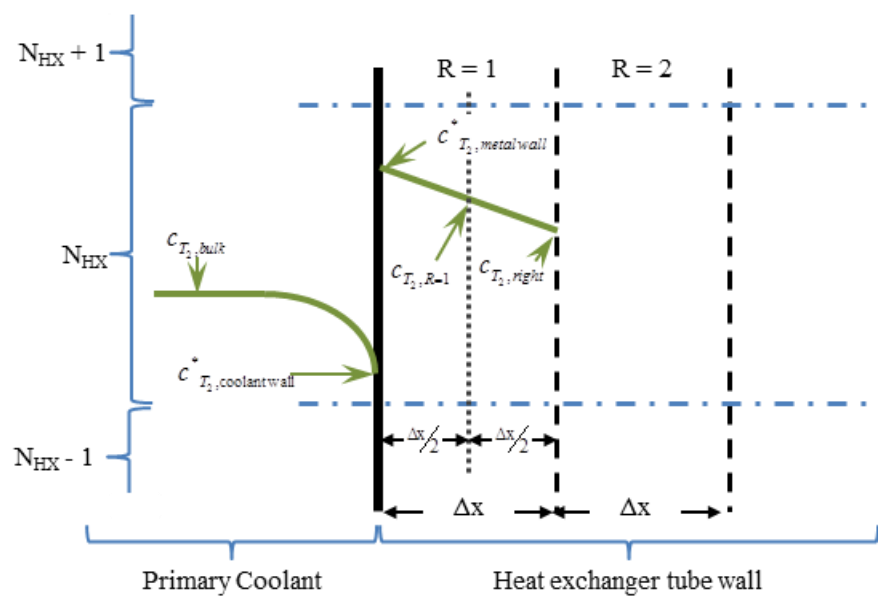

Fig. 6. Schematic concentration profile of $T_{2}$ at the salt/metal interface.

$$
\begin{gathered}
p_{T_{2}, \text { coolant }}=\frac{c_{T_{2}, \text { coolant wall }}^{*}}{k_{\text {Henry }, T_{2}}} \\
p_{T_{2}, \text { metal }}=\left(\frac{c_{T_{2}, \text { metal wall }}^{*}}{K_{S, T_{2}, \text { metal }}}\right)^{2}
\end{gathered}
$$

A second boundary condition is specified at the coolant-metal interface: the flux of $\mathrm{T}_{2}$ from the coolant to the coolant-metal interface (given by Eq. (29)) must be equal to the flux from the interface into the metal (given by Eq. (30)). In Eq. (29), $k_{T 2, p i p e}$ is the mass transfer coefficient for $\mathrm{T}_{2}$ from the salt to the HX tube wall surface, and $c_{T 2 \text {,bulk }}$ is the bulk $\mathrm{T}_{2}$ concentration in flibe away from the tube wall. In Eq. (30), $D$ is the diffusion coefficient of $\mathrm{T}_{2}$ in the metal (in units of $\mathrm{m}^{2} / \mathrm{s}$ ), and $c_{T 2, R=1}$ is the concentration of $T_{2}$ at the center of radial segment $R=1$. The mass transfer coefficient is calculated from correlations and accounts for the temperature, geometry, tritium diffusivity in flibe, and other flibe physical properties (Stempien, 2015). If data specifically for $\mathrm{T}_{2}$ are not available, the diffusion coefficient for $\mathrm{H}_{2}$ is used. Data for $\mathrm{H}_{2}$ could be adjusted according to the kinetic isotope effect, but the scatter in experimental data is larger than the difference this adjustment would make. The concentrations denoted by the letter " $c$ " are in units of mole $\mathrm{T}_{2} / \mathrm{m}^{3}$. Fluxes of $\mathrm{T}_{2}$ are denoted by the letter " $j$ " in units of moles $\mathrm{T}_{2} / \mathrm{m}^{2}$-sec. Tritium diffuses through metal as $\mathrm{T}$ atoms, but the notation here uses $\mathrm{T}_{2}$ throughout for easier accounting. Fig. 6 shows that the thickness of the HX tube wall is divided into a number of radial segments $(\mathrm{R})$, each of thickness $\Delta \mathrm{x}$, at a specific axial segment $\left(\mathrm{N}_{\mathrm{HX}}\right)$ of the $\mathrm{HX},\left(. ., \mathrm{N}_{\mathrm{HX}}-1, \mathrm{~N}_{\mathrm{Hx}}, \mathrm{N}_{\mathrm{Hx}}+1, \ldots\right)$. Detailed diagrams of the discretization scheme employed in TRIDENT are available in reference (Stempien, 2015). The segments containing the coolant-metal interfaces are subdivided into two smaller segments of thickness $\Delta x / 2$. The $T_{2}$ concentration at the center of each segment $\left(c_{T 2, R}\right)$ is assumed to be the average concentration in that segment. The numerical values of each boundary condition will change with each time step $i$ and axial segment of the heat exchanger $\left(N_{H X}\right)$ until equilibrium is reached. Thus, each symbol in the equations below is 
calculated for each $N_{H X}$ and $i$. The equality enforced by this flux boundary condition is that Eq. (29) must equal Eq. (30).

$$
\begin{aligned}
& j_{T_{2}, \mathrm{HX}}^{N_{H X, i}}=k_{T_{2}, \text { pipe }}\left(c_{T_{2}, \text { bulk }}-c_{T_{2}, \text { coolant wall }}^{*}\right) \\
& j_{T_{2}, H X \text { in }}^{N_{H X, i}}=\frac{D}{\Delta \mathrm{x} / 2}\left(c_{T_{2}, \text { metal wall }}^{*}-c_{T_{2}, R=1}\right)
\end{aligned}
$$

Once the concentration and flux boundary conditions have been specified, two conservation equations are required: one for the coolant and one for the first radial segment of the heat exchanger. In Eqs. (31) and (32), $R=1, A^{N H X}{ }_{H X}$ is the surface area $\left(\mathrm{m}^{2}\right)$ of the heat exchanger facing the primary coolant within axial segment $N_{H X}$, and $\Delta t$ is the size of the time step (seconds). Because the heat exchanger is divided into $N_{H X, \text { total }}$ number of axial segments, the size of the time step must also be divided by $N_{H X, \text { total }}$ for calculations within the heat exchanger. $V_{H X}{ }^{N H X}, R$ is the volume of heat exchanger metal in segment $R$ in axial element $N_{H X}$ and $\dot{\mathrm{v}}$ is the coolant volumetric flow rate $\left(\mathrm{m}^{3} / \mathrm{s}\right)$. Eq. (31) calculates a new average concentration of $\mathrm{T}_{2}$ in axial segment $N_{H X}$ and radial segment $R$ in the heat exchanger metal. Eq. (31) incorporates the flux from the coolant to the HX surface defined in Eq. (29). Eq. (32) calculates a new concentration of $\mathrm{T}_{2}$ in the coolant volume element passing through axial segment $N_{H X}$. Eq. (32) incorporates the flux from the metal surface to the center of the radial element $R=1$ in the heat exchanger (defined by Eq. (29)). Eqs. (29), (30), (31), and (32) represent a non-linear system of four equations and four unknowns. The unknowns are $c_{T_{2}, R}{ }^{N_{H X}, i}$, $c_{T_{2} \text {,bulk }}^{N_{H X}, i}, c_{T_{2} \text {,coolant wall }}^{*}$, and $c_{T_{2} \text {,metal wall }}^{*}$. This non-linear system is solved in TRIDENT using the fsolve function in MatLab. Under certain conditions (certain diffusivities and solubilities of tritium in the metal relative to those in the salt) this system can be solved via a faster iterative scheme (Stempien, 2015).

Inside the HX tube wall, tritium diffusion is calculated using an explicit finite difference method which is central difference in space and forward difference in time. It is assumed that the tritium diffusion coefficient does not vary with the tritium concentration and that it is constant through the thickness of the diffusive medium. The temperature is assumed to be constant throughout the thickness of the tube wall. This is a conservative assumption because it keeps the diffusive medium at a temperature higher than it otherwise might be, and the diffusion coefficient is evaluated at this temperature. For tritium diffusing out of the HX and into the air-Brayton power cycle, the concentration of $\mathrm{T}_{2}$ at the metal-power cycle interface is held at 0 . This is the case for the baseline Mk1 PB-FHR. If the FHR being modeled is configured with a secondary system, the same set of equations can be used for tritium diffusing out of the primary heat exchanger and into the secondary coolant and for tritium diffusing from the secondary coolant into the secondary heat exchanger metal (Stempien, 2015). 


$$
\begin{gathered}
c_{T_{2}, R}^{N_{H X}, i}=\frac{c_{T_{2}, R}^{N_{H X}, i-1} \times V_{H X}^{N_{H X}, R}+k_{T_{2}, \text { pipe }}^{i}\left(c_{T_{2}, \text { bulk }}^{N_{H X}, i}-c_{T_{2}, \text { coolant wall }}^{*}\right) \times A_{H X}^{N_{H X}} \times \Delta t / N_{H X, \text { total }}}{V_{H X}^{N_{H X}, R}} \\
c_{T_{2}, \text { bulk }}^{N_{H X}, i}=\frac{c_{T_{2}, \text { bulk }}^{N_{H X}, i-1} \times \dot{\mathrm{v}} \times \Delta t-\frac{D}{\Delta \mathrm{x} / 2}\left(c_{T_{2}, \text { metal wall }}^{*}-c^{N_{H X, i}{ }_{T_{2}, R_{1} / 2}}\right) \times A_{H X}^{N_{H X}} \times \Delta t / N_{H X, \text { total }}}{\dot{\mathrm{v}} \times \Delta t}
\end{gathered}
$$

Metal oxides are renowned for their low hydrogen permeabilities (Causey et al., 2012). A term called the permeation reduction factor (PRF) is used as a metric for comparing the effectiveness of permeation barriers. The PRF is the ratio of the permeability of a material without a permeation barrier to the permeability of a material with a permeation barrier (Causey et al., 2012). Hollenberg et. al. provide a review of PRFs for oxide layers on steel and stainless steel base metals (Hollenberg et al., 1995). For stainless steels, the natural oxide layer is mainly chromium oxide $\left(\mathrm{Cr}_{2} \mathrm{O}_{3}\right)$ which affords a PRF of 10 to 20 on austenitic stainless steels (Hollenberg et al., 1995; Oya et al., 2012). Specially applied coatings may offer higher PRFs of 1000 or higher.

While metal oxides make effective hydrogen permeation barriers, they are not thermodynamically stable when facing fluoride salts. Thus metal oxide layers would not exist on the salt-facing surface of the metal. However, the air-facing surface of the salt-to-air heat exchanger will have an oxide layer. This layer is accounted for in TRIDENT by use of a baseline PRF of 10 for austenitic stainless steels such as Type $316 \mathrm{~L}$, which may be used in FHRs. This effect is implemented by dividing the diffusion coefficient $(D)$ by the PRF at the surface node and at each point in the tube-wall thickness. Since the oxide layer does not face the salt, it cannot prevent tritium from entering the metal, but it may slow the movement of tritium out of the down-stream side of the metal.

\subsection{Benchmarking of the tritium transport model in TRIDENT}

While data from a forced-convection polythermal loop of molten salt containing tritium do not exist for comparison, tritium transport calculations in TRIDENT can be compared to data from static salt diffusion tests carried out within special test capsules. Two such tests will be used for benchmarking here. One test involves tritium diffusion through $\mathrm{Ni}$ and flibe, and the other test involves tritium diffusion through $\mathrm{Ni}$ and flinak (0.465LiF-0.115NaF-0.42KF). Fukada and Morisaki measured the permeability of hydrogen $\left({ }^{1} \mathrm{H}\right)$ through nickel and flinak using a specialized apparatus pictured in Figure 1 of (Fukada and Morisaki, 2006). In the volume below the Ni membrane, a constant pressure and flow-rate of a mixture of $\mathrm{H}_{2}$ and $\mathrm{Ar}$ gas was applied to the bottom surface of the Ni. The thickness of the Ni membrane was $2.0 \mathrm{~mm}$. Hydrogen permeated through this $\mathrm{Ni}$ membrane into the flinak in contact with the upper surface of the Ni membrane. The standard thickness of flinak used in the measurements was $20.0 \mathrm{~mm}$, but salt thicknesses up to $40.0 \mathrm{~mm}$ were also used. Because the TRIDENT model keeps a mass balance of tritium in every volume (including within the metal membrane), the volume of the Ni membrane must be known. Besides the thickness 
of the Ni membrane, Fukada and Morisaki do not provide any other dimensional data for the membrane in reference (Fukada and Morisaki, 2006). Despite this ambiguity, the area of the Ni membrane is set to $20 \mathrm{~cm}^{2}$. This is done for several reasons. The apparatus used by Calderoni et. al. was provided by Fukada, is the same apparatus used by Fukada in (Fukada and Morisaki, 2006), and the membrane measures $2.52 \mathrm{~cm}$ in radius $\left(19.95 \mathrm{~cm}^{2}\right.$ ) from Figure 1 in (Calderoni et al., 2008). Furthermore, the apparatus used by Fukada et. al. in measurements of hydrogen permeation in Li-Pb appears to be identical to that used in (Fukada and Morisaki, 2006), and the listed cross-sectional area for that membrane is $20 \mathrm{~cm}^{2}$ (Fukada et al., 2012). The input values required for TRIDENT to simulate the time dependent permeation of hydrogen in this system are listed in Table 3.

Table 3

Input required for TRIDENT to simulate experiments performed in (Fukada and Morisaki, 2006) and generate Fig. 8.

\begin{tabular}{|l|c|}
\hline & Input Units and References \\
\hline Temperature & Various [K] from (Fukada and Morisaki, 2006) \\
\hline Ni membrane thickness & $0.002[\mathrm{~m}]$ from (Fukada and Morisaki, 2006) \\
\hline Ni membrane area & 0.002 [m $\left.{ }^{2}\right]$ (Calderoni et al., 2008) \\
\hline Flinak thickness & Various [m] from (Fukada and Morisaki, 2006) \\
\hline $\mathrm{H}_{2}$ charge (input) pressure & Various [Pa] from (Fukada and Morisaki, 2006) \\
\hline $\mathrm{H}_{2}$ upstream pressure above the salt & Set to 0 for all calculations. [Pa] \\
\hline Henry's law constant for $\mathrm{H}_{2}$ in flinak & {$\left[\mathrm{mol} / \mathrm{m}^{3}-\mathrm{Pa}\right]$ from (Fukada and Morisaki, 2006) } \\
\hline Diffusivity of $\mathrm{H}_{2}$ in flinak & {$\left[\mathrm{m}^{2} / \mathrm{s}\right]$ (Stempien, 2015) corrected mistake in } \\
& $\left(\right.$ Fukada and Morisaki, 2006) $^{2}$ \\
\hline Diffusivity of hydrogen in $\mathrm{Ni}$ & {$\left[\mathrm{m}^{2} / \mathrm{s}\right]$ from (Tanabe et al., 1984) } \\
\hline Sieverts' law constant for $\mathrm{H}_{2}$ in $\mathrm{Ni}$ & {$\left[\mathrm{mol}^{3} / \mathrm{m}^{3}-\mathrm{Pa}^{0.5}\right.$ from (Tanabe et al., 1984) } \\
\hline
\end{tabular}

The time-dependent behavior was simulated in TRIDENT at 600,650 , and $700{ }^{\circ} \mathrm{C}$ for a flinak thickness of $20 \mathrm{~mm}$ and a fixed $\mathrm{H}_{2}$ charge pressure of $1.01 \times 10^{5} \mathrm{~Pa}$, the same conditions used by Fukada and Morisaki (Fukada and Morisaki, 2006). ${ }^{1}$ Fukada and Morisaki reported the time dependence of the downstream hydrogen concentration in the sweep gas used in the volume above the flinak. TRIDENT does not calculate this value. So in order to compare this behavior, the time dependence of the hydrogen permeation flux calculated in TRIDENT was normalized against its steady state value. Likewise, the sweep-gas hydrogen concentration from Fukada and Morisaki was normalized against its steady state value. Only the results from the simulation at $700{ }^{\circ} \mathrm{C}$ are reported here in Fig. 7. The results from the simulations at 600 and $650{ }^{\circ} \mathrm{C}$ were comparable and are available in (Stempien, 2015).

\footnotetext{
${ }^{1}$ The label of $\mathrm{L}_{\mathrm{flinak}}=40 \mathrm{~mm}$ in Figure 2 of (Fukada and Morisaki, 2006) is wrong. The correct label is $\mathrm{L}_{\mathrm{flinak}}=20$ $\mathrm{mm}$. This is verified by using equation (A.2) from (Fukada and Morisaki, 2006) to reproduce this figure. A flinak thickness of $20 \mathrm{~mm}$ was used in TRIDENT for these time-dependent calculations.
} 


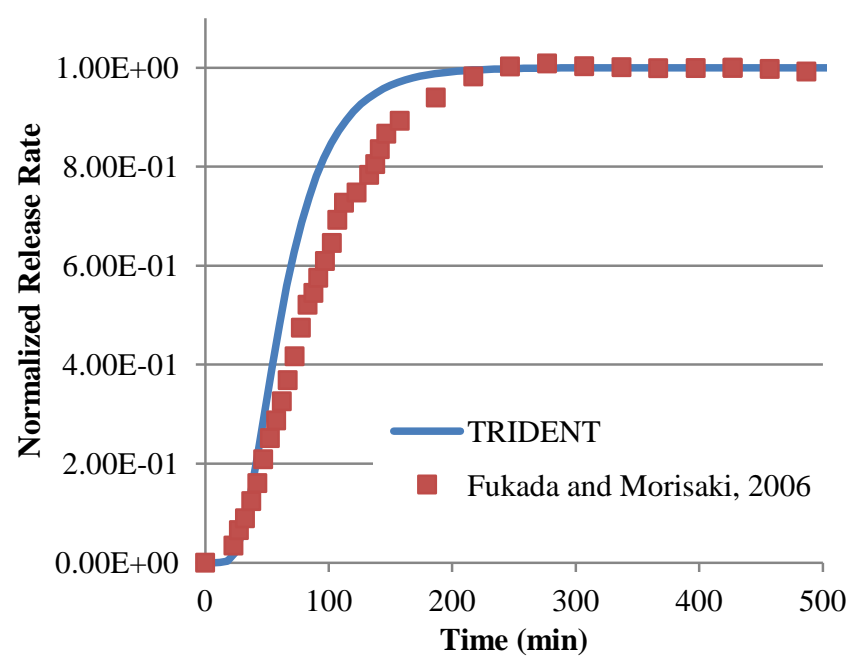

Fig. 7. Normalized hydrogen permeation metrics for hydrogen permeation through the apparatus illustrated in Figure 1 of (Fukada and Morisaki, 2006). Solid line calculated with TRIDENT. Points from Figure 2 in (Fukada and Morisaki, 2006).

Fig. 7 shows that TRIDENT's modeling of transient behavior is in good agreement with experiment. The following figures show the consistency with which TRIDENT can match the steady-state hydrogen permeation fluxes determined from experiment. Good agreement is observed, especially at the higher temperatures (above $500{ }^{\circ} \mathrm{C}$ ) and lower hydrogen pressures which will characterize FHR operation. Discrepancies between TRIDENT and the experimental values could exist due to experimental uncertainties and the choice of the diffusion coefficient and Sieverts' law constant used in TRIDENT for the Ni membrane. It was assumed in the calculations that all tritium existed in the salt in the experiments as $\mathrm{T}_{2}$; however, the redox potential of the salt in the experiment was not controlled, and if any moisture entered the system, it would have made HF and some tritium could have exchanged with $\mathrm{H}$ in $\mathrm{HF}$ to make TF, which would not diffuse through nickel. Fig. 8 shows the steady-state hydrogen permeation flux at three different temperatures for a system with a hydrogen input pressure of $101 \mathrm{kPa}$ and salt thicknesses of $20 \mathrm{~mm}$ or $40 \mathrm{~mm}$. The open symbols were extracted from the data in Figure 4 of (Fukada and Morisaki, 2006). The solid symbols were calculated with TRIDENT. Close agreement is observed in all cases. In a different comparison (not reported here) the steady-state hydrogen permeation flux for a flinak thickness of $20 \mathrm{~mm}$, over a range of temperatures and input hydrogen pressures was compared between the data in Figure 3 of (Fukada and Morisaki, 2006) and TRIDENT (Stempien, 2015). Close agreement was observed in all cases.

Calderoni et. al. measured the tritium permeation flux using the same apparatus as that used by (Fukada and Morisaki, 2006). In their experiment, they used $\mathrm{T}_{2}$ gas and a layer of flibe on top of the Ni membrane. The diffusivity of $\mathrm{T}_{2}$ in flibe and the Henry's law constant for $\mathrm{T}_{2}$ in flibe were also measured. Table 4 summarizes the input parameters required for TRIDENT to simulate these experiments. Fig. 9 shows TRIDENT calculations compared to the data reported in Figure 2 of (Calderoni et al., 2008). TRIDENT compares well with this experiment, although some deviation occurs at higher temperatures when higher hydrogen input pressures are used. Calderoni et. al. note 
that their Henry's law constant measured for $\mathrm{T}_{2}$ in flibe more closely matches the Henry's law constant for TF in flibe measured by Field and Shaffer (Calderoni et al., 2008; Field and Shaffer, 1967). This suggests that the redox condition in the flibe used by Calderoni et. al. may have been more oxidizing. This may also contribute to the difference, because for these calculations, TRIDENT was operated under the assumption that all tritium existed in the salt in the reduced state, $\mathrm{T}_{2}$.

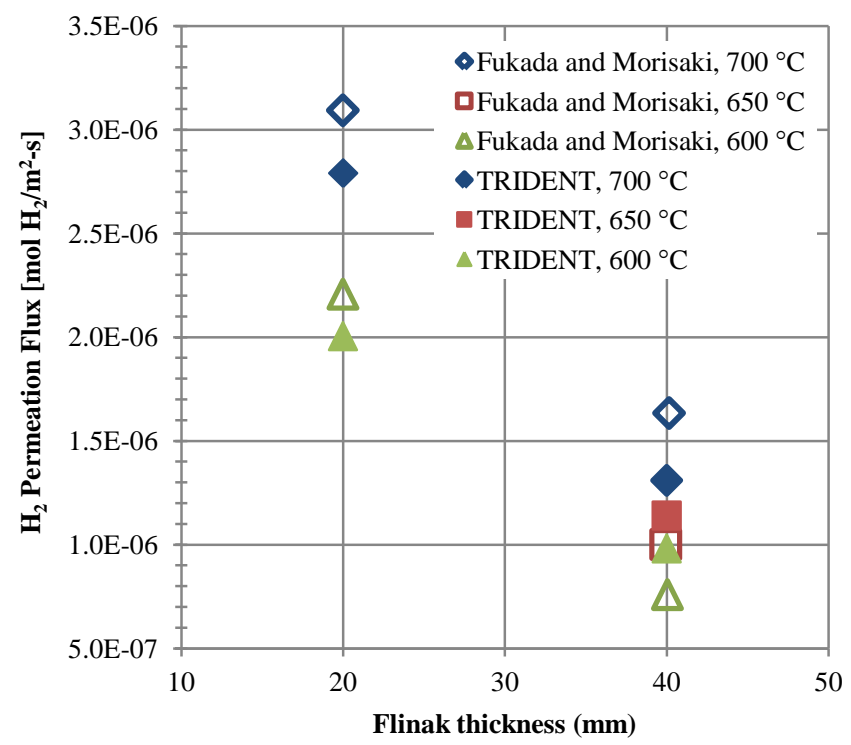

Fig. 8. Steady-state $\mathrm{H}_{2}$ flux in apparatus used in (Fukada and Morisaki, 2006). Solid symbols calculated with TRIDENT.

Table 4

Input required for TRIDENT to simulate experiments performed in (Calderoni et al., 2008) and generate Fig. 9.

\begin{tabular}{|c|c|}
\hline & Input Units and References \\
\hline Temperature & Variable $[\mathrm{K}]$, (Calderoni et al., 2008) \\
\hline $\begin{array}{c}\text { Ni membrane } \\
\text { thickness }\end{array}$ & 0.002 [m] (Calderoni et al., 2008) \\
\hline Ni membrane area & $0.002\left[\mathrm{~m}^{2}\right]$ (Calderoni et al., 2008) \\
\hline Flibe thickness & 0.0081 [m] (Calderoni et al., 2008) \\
\hline $\begin{array}{l}\mathrm{T}_{2} \text { charge (input) } \\
\text { pressure }\end{array}$ & Variable [Pa], (Calderoni et al., 2008) \\
\hline $\begin{array}{c}\mathrm{T}_{2} \text { upstream } \\
\text { pressure above the } \\
\text { salt }\end{array}$ & Set to 0 for all calculations. $[\mathrm{Pa}]$ \\
\hline $\begin{array}{c}\text { Henry's law } \\
\text { constant for } \mathrm{T}_{2} \text { in } \\
\text { flibe from ref }\end{array}$ & $\begin{array}{c}{\left[\mathrm{mol} / \mathrm{m}^{3}-\mathrm{Pa}\right], \text { Equation } 7 \text { in (Calderoni }} \\
\text { et al., 2008) }\end{array}$ \\
\hline $\begin{array}{l}\text { Diffusivity of } \mathrm{T}_{2} \text { in } \\
\text { flibe }\end{array}$ & $\begin{array}{c}{\left[\mathrm{m}^{2} / \mathrm{s}\right] \text {, Equation } 6 \text { in (Calderoni et al., }} \\
\text { 2008) }\end{array}$ \\
\hline $\begin{array}{c}\text { Diffusivity of } \\
\text { hydrogen in } \mathrm{Ni}\end{array}$ & {$\left[\mathrm{m}^{2} / \mathrm{s}\right]$ from (Tanabe et al., 1984) } \\
\hline $\begin{array}{c}\text { Sieverts' law } \\
\text { constant for } \mathrm{T}_{2} \text { in } \\
\mathrm{Ni}\end{array}$ & $\begin{array}{c}{\left[\mathrm{mol} / \mathrm{m}^{3}-\mathrm{Pa}^{0.5}\right] \text { from (Tanabe et al., }} \\
1984)\end{array}$ \\
\hline
\end{tabular}




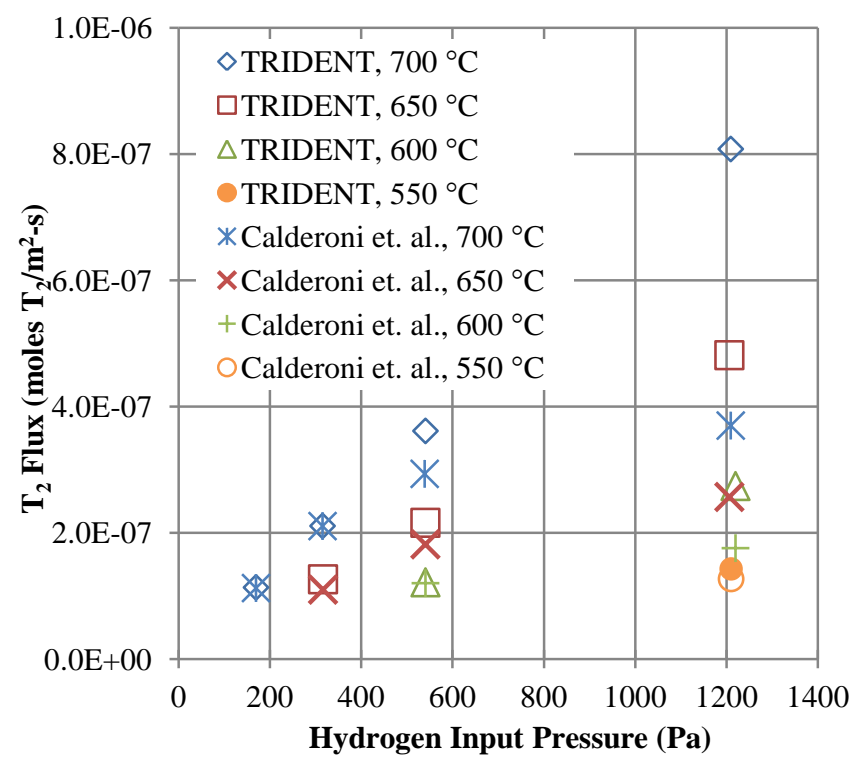

Fig. 9. Tritium permeation flux through nickel/flibe. Solid symbols calculated with TRIDENT.

\section{Corrosion modeling}

In Section 4, it was established that in structural alloys (comprised of $\mathrm{Fe}, \mathrm{Ni}$, and $\mathrm{Cr}$ ), $\mathrm{Cr}$ is the most vulnerable element for oxidation by impurities in flibe. In fact, an analysis of corrosion in fluoride salts can focus on $\mathrm{Cr}$ (the least noble structural metal) because appreciable $\mathrm{Fe}$ and $\mathrm{Ni}$ corrosion does not occur (Keiser, 1977; Koger, 1972a; Williams et al., 2006).

In a coolant system in which temperature varies throughout the loop, there are several mechanisms which affect the location and rates of corrosion. Corrosion rates are initially high (compared to steady-state rates) as surface $\mathrm{Cr}$ is corroded and impurities in the salt are consumed through redox reactions with $\mathrm{Cr}$ (Keiser et al., 1977; Koger, 1972b, 1972a). For salts containing $\mathrm{UF}_{4}$ (such as in the MSRE or in a Molten Salt Breeder Reactor) or salts in which TF is continually produced from neutron transmutation (such as MSRs and FHRs), long-term corrosion can occur at lower rates (Evans III et al., 1961; Koger, 1972a). Long-term corrosion rates are governed by the rate of $\mathrm{Cr}$ diffusion to the metal surface (Evans III et al., 1961; Ignatiev and Surenkov, 2012; Koger, 1972a; Williams et al., 2006). More specifically, experimental findings suggest that the corrosion rate is governed by grain boundary diffusion of $\mathrm{Cr}$, rather than bulk diffusion. This is true in the nickel-base alloy Hastelloy-N, but it is especially evident in austenitic stainless steels such as types 304 and 316 (Koger, 1972b; Kondo et al., 2009a, 2009b). Additionally, experiments have shown that selective Cr corrosion can produce subsurface voids in the metal due to the Kirkendall effect where $\mathrm{Cr}$ diffuses out of the metal (by a vacancy process) faster than $\mathrm{Fe}, \mathrm{Ni}$, and other alloying elements can diffuse in to fill the Cr vacancies (Koger, 1972a). 


\subsection{Determination of corrosion versus deposition reactions}

TRIDENT uses a simple logic for determining whether corrosion or deposition reactions occur in a particular part of a coolant loop. First, TRIDENT evaluates an equation such as Eq. (24) (for corrosion of $\mathrm{Cr}$ by $\mathrm{TF}$ ) or Eq. (26) (for corrosion of $\mathrm{Cr}$ by $\mathrm{UF}_{4}$ as would occur in an MSR) at each point along the primary coolant loop in order to determine the local equilibrium concentration of dissolved $\mathrm{CrF}_{2}$. If the actual concentration of $\mathrm{CrF}_{2}$ in the salt flowing into a given loop segment is less than the local equilibrium concentration of $\mathrm{CrF}_{2}$, then corrosion according to Eq. (21) (in FHRs) or Eq. (25) (in MSRs) is allowed. On the other hand, if the actual concentration of $\mathrm{CrF}_{2}$ in the salt entering a given segment is greater than the local equilibrium concentration of $\mathrm{CrF}_{2}$ in that segment, then deposition/precipitation of Cr onto surfaces in that region is allowed according to the inverse of Eq. (21) (in FHRs) or Eq. (25) (in MSRs).

The general equation for the flux of $\mathrm{Cr}$ from the salt to a surface for deposition is given by Eq. (33). Here the deposition flux is given by $j_{\text {deposition }}$ in units of $\mathrm{mol} \mathrm{Cr} / \mathrm{m}^{2}$-s. The mass transfer coefficient for transport of dissolved $\mathrm{Cr}$ to a given surface is given by $k_{C r}$. The actual concentration of $\mathrm{Cr}$ in the salt is given by $c_{C r \text {,actual }}$ and the local equilibrium concentration of dissolved $\mathrm{Cr}$ is given

by $c_{C r, e q}$ (in units of mole/m³ ${ }^{3}$. Eq. (21) (in FHRs) or Eq. (25) (in MSRs) are used to calculate $c_{C r, e q}$. Eq. (33) was written so that deposition would occur until the concentration of $\mathrm{Cr}$ in the salt is equal to the local equilibrium concentration. Since chemical reaction rate data for the deposition of $\mathrm{Cr}$ are not available, this treatment assumes that the rate of deposition is equal to the mass flux of $\mathrm{Cr}$ calculated in Eq. (33).

$$
j_{\text {deposition }}=k_{C r}\left(c_{C r, a c t u a l}-c_{C r, e q}\right)
$$

Two phases of corrosion are modeled. First, if the logic above has determined that Cr oxidation will occur, then the initial corrosion rates are dictated by the mass transfer rate of a chemical oxidant to the metal surface (Koger, 1972a). Any pre-existing Ni fluoride and Fe fluoride impurities can also be consumed in this period, and this consumption generally goes to completion (Keiser, 1977; Koger, 1972a). Since the contribution of $\mathrm{NiF}_{2}$ and $\mathrm{FeF}_{2}$ impurities to $\mathrm{Cr}$ corrosion is limited to early exposure times, these reactions are currently neglected in the model developed here. For the purposes of this model, the metal surface over which initial corrosion occurs is defined as the thickness of metal from the metal/coolant interface down to a depth in the metal specified by the lattice parameter $(\delta)$ of that metal.

Once all of the $\mathrm{Cr}$ has been corroded from this surface of thickness $\delta$, the second phase of corrosion begins, and the rate of $\mathrm{Cr}$ corrosion is determined by the combined effects of the $\mathrm{Cr}$ grainboundary and bulk diffusion rates. Grain boundaries (GBs) are not explicitly modeled; however, the surface area available for corrosion is altered to correspond to the GB surface area facing the coolant. A hexagonal grain shape is assumed. At left in Fig. 10, the interface between three hexagonal grains is depicted, and on the right side of Fig. 10, the grain triple-point is highlighted. The width of the grain boundary (the space between adjoining grains) is symbolized as $w_{g b}$. The grain size (also called 
the grain diameter) is given by the distance between the flats $(d)$ of the hexagonal grains. Based on the type of metal used for the piping, the grain boundary diameter $d$ can be specified in the model. The grain boundary diameter is used to calculate the length $s$ of the side of a hexagonal grain $(s=$ $d / \sqrt{3}$ ). The side length $s$ and grain boundary width $w_{g b}$ are used to calculate the radius $r$ of a hypothetical circle surrounding a grain triple point according to Eq (34) (Stempien, 2015). This hypothetical circle surrounds the triple-point and passes through the three grain vertices at a distance $r$ from the triple point. In Eq (34), this radius is equal to the length of a side $(s)$ of the hexagonal grain plus the contribution from the grain boundary width at the triple point (Stempien, 2015). The area of the circle $\left(A_{\text {circle }}\right)$ is calculated by the familiar equation given in Eq (35). The grain boundary surface area $\left(A_{g b}\right)$ within the circle is given by Eq (36). The ratio of the grain boundary surface area $\left(A_{g b}\right)$ to the bulk metal surface area (represented by $A_{\text {circle }}$ ) is given by Eq (37), which is used later on in Eq (42). This approach was adopted so that the total area of all of the grain boundaries within sections of a reactor system could be calculated. Eq (34) through Eq (37) allow a calculation of the ratio of the grain boundary surface area to the macro surface area (Stempien, 2015). If, for example the ratio calculated in Eq (37) is 4E-4, then the grain boundary surface area is $4 \mathrm{~m}^{2}$ in a heat exchanger with a macroscopic surface area of $10000 \mathrm{~m}^{2}$.

The first phase of corrosion (limited by the rate of oxidant mass transport) leaves a metal surface that has a metallic $\mathrm{Cr}$ concentration of 0 . This allows the use of a well-known analytical solution to the 1D time-dependent diffusion problem. For selective $\mathrm{Cr}$ corrosion without surface recession, the $\mathrm{Cr}$ concentration in the metal as a function of the depth in the metal $(x)$ and the exposure time $(t)$ is given by Eq (38) (Anno and Walowit, 1971; Zhang et al., 2010). This equation assumes that the surface concentration is constant at 0 , that the metal can be treated as having infinite thickness compared to the depth of corrosion losses, and that the $\mathrm{Cr}$ concentration deep within the metal $\left(c_{C r, m}\right)$ remains constant. The diffusion coefficient of $\mathrm{Cr}$ in the metal is given by $D_{C r}$ in units $\mathrm{of} \mathrm{m}^{2} / \mathrm{s}$ and the $\mathrm{Cr}$ concentrations are given in units of mole $\mathrm{Cr} / \mathrm{m}^{3}$ metal. In order to determine the flux of $\mathrm{Cr}$ from within the metal to the metal surface at a given time $t$, the Cr concentration gradient must be known. For this purpose, Eq (38) is solved for $x$ in order to give Eq (39), which is used to calculate the depth in the metal $\left(x_{99 \%}\right)$ at which the $\mathrm{Cr}$ concentration is $99 \%$ of the bulk metal $\mathrm{Cr}$ concentration (Stempien, 2015). The depth at which the concentration is $99 \%$ of the original bulk concentration was selected (somewhat arbitrarily) in order to determine a gradient between the surface and the point at which the concentration profile has flattened (Stempien, 2015). Knowing the concentration at $99 \%$ of the bulk concentration $\left(c_{C r, 99 \%}=0.99 c_{C r, m}\right)$ and the depth $x_{99 \%}$, the flux of Cr from the metal bulk to the metal surface $\left(j_{C r, m}\right)$ can be calculated according to Eq (40) (Ficks' first law of diffusion) where the concentration of $\mathrm{Cr}$ on the metal side of the metal-salt interface is equal to zero $\left(c_{C r \text {,surface }}=\right.$ 0 ). In order to determine the flux of $\mathrm{Cr}$ to the metal-salt interface due to grain boundary diffusion, $D_{C r}$ in Eqs (38) through (40) is set to the Cr grain boundary diffusion coefficient. In order to determine the flux of $\mathrm{Cr}$ to the metal-salt interface due to bulk $\mathrm{Cr}$ diffusion, the bulk $\mathrm{Cr}$ diffusion coefficient in the base metal is used in Eqs. (38) through (40). 


$$
\begin{gathered}
r=s+\frac{\sqrt{3} \times w_{g b}}{4} \\
A_{\text {circle }}=\pi r^{2} \\
A_{g b}=3 d w_{g b}+\frac{\sqrt{3}}{4} w_{g b}^{2} \\
\text { Area ratio }{ }_{g b / \text { bulk }}=A_{g b} / A_{\text {circle }} \\
c_{C r}(x, t)=c_{C r, \mathrm{~m}} \operatorname{erf}\left(\frac{x}{2 \sqrt{D_{C r} t}}\right) \\
x_{99 \%}=2 \sqrt{D_{C r} t} \operatorname{erf}{ }^{-1}(0.99) \\
j_{C r, m}=\frac{D_{C r}}{x_{99 \%}}\left(c_{C r, 99 \%}-c_{C r, \text { surface }}\right)
\end{gathered}
$$

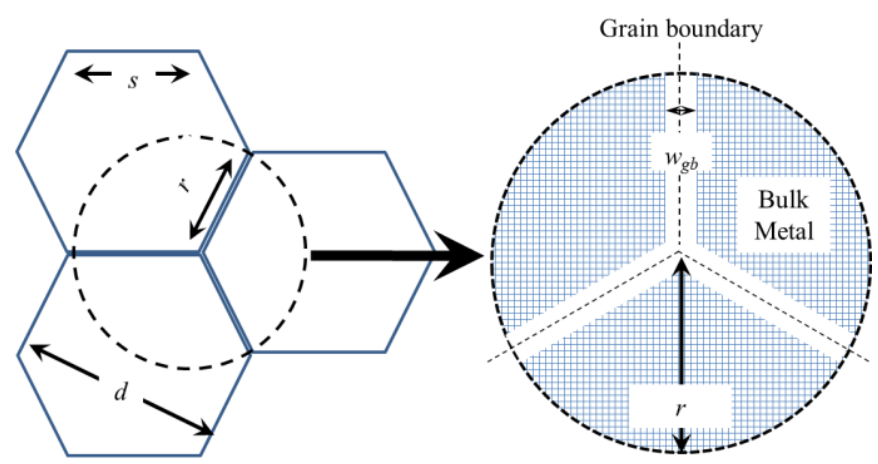

Fig. 10. Grain boundary representation used to estimate grain boundary surface area per unit bulk metal surface area.

The contributions from both bulk diffusion and grain boundary diffusion are calculated, although, as was mentioned above, grain boundary diffusion is the dominant rate-determining step of $\mathrm{Cr}$ loss from the metal to the salt. The moles of $\mathrm{Cr}$ lost due to corrosion limited by the bulk diffusion mechanism at a location in the loop having a surface area $S A\left(\mathrm{~m}^{2}\right)$ during a time step of duration $\Delta T$ $(\mathrm{sec})$ is given by Eq (41). To calculate $j_{C r, m}$ for use in Eq (41), $D_{C r \text {,bulk }}$ is used in Eqs (38) through (40) above. The amount of $\mathrm{Cr}$ corroded from the grain boundaries in a segment of the coolant loop having a bulk surface area $S A$ during a time step of duration $\Delta t$ is given by Eq (42). To calculate $j_{C r, m}$ for use in Eq (42), $D_{C r, g b}$ is used in Eqs (38) through (40) above. At early times, the flux of Cr to the salt-metal interface via the grain boundary mechanism may be calculated to exceed the rate of TF mass transfer to the metal surface. In this instance then, the rate of $\mathrm{Cr}$ diffusion/corrosion is set equal to $1 / 2$ the rate of TF mass transfer to the surface such that Eq. (21) is satisfied.

$$
\begin{gathered}
\text { Cr corroded via bulk diffusion mechanism }=j_{C r, m} \times S A \times \Delta t \\
\text { Cr corroded via grain boundary diffusion }=j_{C r, m} \times S A \times \text { Area Ratio }{ }_{g b / b u l k} \times \Delta t
\end{gathered}
$$




\subsection{Corrosion model benchmarking}

A number of natural circulation and forced convection corrosion loops (sometimes referred to as "harps" due to their shape) were operated with different metals and fluoride salts between the 1950s and early 1970s at ORNL. The basic loop parameters for several tests are available in ORNL reports from that period (Keiser, 1977; Keiser et al., 1977; Koger, 1972b, 1972a). Information such as the salt type, salt maximum and minimum temperatures, loop metal, duration of test, and the weight change of samples during the test is available for several loops. Using input from the ORNL corrosion reports, a benchmark of the corrosion model in TRIDENT was performed.

The first loop that was analyzed using the corrosion model in TRIDENT was the natural convection loop (NCL) 21A which operated at ORNL for 10,000 hours beginning in 1974 (Keiser, 1977). A schematic of NCL-21A is shown in Fig. 11. The corrosion model in TRIDENT requires a number of input parameters, and no loop experiment at ORNL reports all of the required parameters. Thus, some approximations and estimations were made in order to build a model of the loop in TRIDENT. Additionally, the loop treatment in TRIDENT is of lower fidelity than the actual experiments. For example, the surge tanks in Fig. 11 were not modeled in TRIDENT. TRIDENT requires knowledge of the length of piping in each section of the loop so that the length of the heated and un-heated sections is known. The length of each pipe segment was estimated based on Fig. 11. The lower leg and the left vertical leg have heating elements, but the rest of the loop is un-heated and un-insulated. The temperature profile around the loop is not known, but a constant linear heating or cooling rate along each segment was assumed. The outer diameter of the Hastelloy-N tubing used to construct Loop 21A was $1.905 \mathrm{~cm}(0.75$ inches $)$ with a tube wall thickness of $0.1823 \mathrm{~cm}(0.072$ inches) (Koger, 1972b). The average salt flow velocity in Loop 21A was $1 \mathrm{~m} /$ minute (Keiser, 1977). The chemical composition of the Hastelloy- $\mathrm{N}$ tubing is given in (Koger, 1972b). The maximum and minimum loop temperatures were $704{ }^{\circ} \mathrm{C}$ and $566{ }^{\circ} \mathrm{C}$, respectively (Keiser, 1977). A series of Hastelloy-N samples were placed throughout Loop 21A, and the weight change of the samples was measured periodically. Since the exact placement of these samples was not reported, this benchmark uses TRIDENT to calculate the weight change of the Hastelloy-N piping used to construct the loop. These weight changes were then compared to the weight changes for the samples reported in reference (Keiser, 1977). The salt used in Loop 21A was the molten salt breeder reactor fuel salt comprised of $\mathrm{LiF}_{-} \mathrm{BeF}_{2}-\mathrm{ThF}_{4}-\mathrm{UF}_{4}$ (72-16-11.7-0.3 mole \%) (Keiser, 1977). The temperature dependent density of this fuel salt was reported in Table 3.1 of reference (Rosenthal et al., 1971). This density was used in the simulation. Because relevant properties for fueled salts do not exist, all of the other coolant properties used in the simulation are those reported for clean flibe $(0.67 \mathrm{LiF}-0.33$ $\mathrm{BeF}_{2}$ ). In a fueled salt, the principle corrosion reaction of $\mathrm{Cr}$ is with $\mathrm{UF}_{4}$ according to Eq. (25), and the equilibrium concentration of dissolved $\mathrm{Cr}$ as a function of temperature and the $\mathrm{UF}_{4}: \mathrm{UF}_{3}$ ratio is given by Eq. (26). The initial ratio of $\mathrm{UF}_{4}$ to $\mathrm{UF}_{3}$ in Loop $21 \mathrm{~A}$ was 10,000:1 (Keiser, 1977). Compared to the typical MSRE ratio of 100:1, the salt in Loop 21A is more oxidizing. The initial concentration of $\mathrm{Cr}$ in the salt was not reported. A well-prepared salt generally has about $25 \mathrm{ppm} \mathrm{Cr}$ 
(Shaffer, 1971). Thus, $25 \mathrm{ppm} \mathrm{Cr}$ in the salt was specified as the initial concentration for the benchmark. The grain boundary diffusion coefficient for $\mathrm{Cr}$ in Hastelloy-N is not available, thus $D_{C r, g b}$ for Type 316 SS was used (Mizouchi et al., 2004). The diffusion coefficient for bulk Cr diffusion in Hastelloy-N is from (Evans III et al., 1961). Finally, the grain size and grain boundary width of the Hastelloy-N piping are required for use in Eqs. (34) through (42). Since these parameters were not reported, it was estimated that the grain boundary width is 10 atomic spacings $(3.3 \mathrm{~nm}$ ) based on the Van der Waals radius for nickel. The grain size reported for Hastelloy-X (24 $\mu \mathrm{m}$ ) was adopted here for Hastelloy-N (Abuzaid et al., 2013), and a lattice parameter of $1.1 \mathrm{~nm}$ was used (Gehlbach and McCoy, 1968).

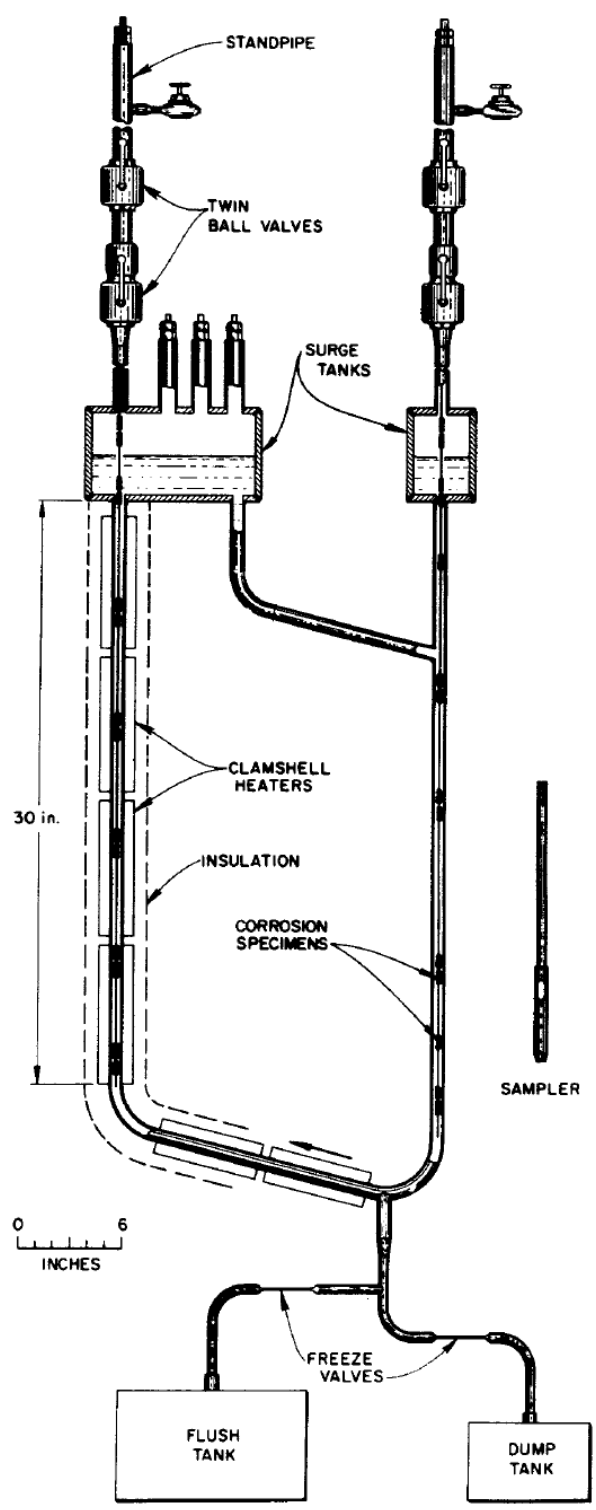

Fig. 11. Schematic of Loop NCL-21A. Figure from (Keiser, 1977). 
In Fig. 3 of reference (Keiser, 1977), the weight changes of samples at $566{ }^{\circ} \mathrm{C}, 635^{\circ} \mathrm{C}$, and 704 ${ }^{\circ} \mathrm{C}$ in Loop 21A are plotted as a function of exposure time. The program DataThief was used to extract these data in order to compare with the results from a TRIDENT simulation of Loop 21A. These data along with the results from a TRIDENT simulation are plotted in Fig. 12. After 10,000 hours, the net weight change in the hottest section of the loop $\left(704{ }^{\circ} \mathrm{C}\right)$ calculated by TRIDENT is about $-2 \mathrm{mg} / \mathrm{cm}^{2}$ compared to about $-3.5 \mathrm{mg} / \mathrm{cm}^{2}$ from experimental data of loop $21 \mathrm{~A}$. After 10,000 hours, the experimental weight gain in a sample at $635^{\circ} \mathrm{C}$ was about $0.5 \mathrm{mg} / \mathrm{cm}^{2}$. In comparison, the TRIDENT simulation calculated a net weight change of about $-1 \mathrm{mg} / \mathrm{cm}^{2}$ at $635^{\circ} \mathrm{C}$. The weight gain calculated by TRIDENT at $573{ }^{\circ} \mathrm{C}\left(1.5 \mathrm{mg} / \mathrm{cm}^{2}\right)$ has a similar value after 10,000 hours as that measured at $566{ }^{\circ} \mathrm{C}\left(1.3 \mathrm{mg} / \mathrm{cm}^{2}\right)$. After 10,000 hours, TRIDENT calculates a weight gain of about $60 \mathrm{mg} / \mathrm{cm}^{2}$ at $566{ }^{\circ} \mathrm{C}$ (compared to $1.3 \mathrm{mg} / \mathrm{cm}^{2}$ from experiment).

The difference between the weight change simulated with TRIDENT and the experimental data at $704{ }^{\circ} \mathrm{C}$ is reasonable given the estimations and approximations required to model Loop $21 \mathrm{~A}$ in TRIDENT. The fact that TRIDENT under-predicts weight loss at $704{ }^{\circ} \mathrm{C}$ could be due to the fact that the Cr grain boundary diffusion coefficient (which limits the long-term $\mathrm{Cr}$ corrosion rate) for Hastelloy-N has not been measured, and a grain boundary diffusion coefficient for Type 316 SS was used in the calculation. In another nickel-base alloy, Inconel-600, the $\mathrm{Cr}$ grain boundary diffusion coefficient is about 2.5 times higher than in Type 316 SS (Mizouchi et al., 2004; Pruthi et al., 1977). If a higher $\mathrm{Cr}$ grain boundary diffusion coefficient had been used in the simulation, the weight loss predicted at $704{ }^{\circ} \mathrm{C}$ would be greater. The fact that TRIDENT predicts weight loss at $635{ }^{\circ} \mathrm{C}$ while the experiment measured slight weight gain is likely due to the under-prediction of weight loss at 704 ${ }^{\circ} \mathrm{C}$ upstream of the $635^{\circ} \mathrm{C}$ location. With an under-prediction of the dissolved $\mathrm{Cr}$ content upstream of $635^{\circ} \mathrm{C}$, this would result in delayed transition from weight loss to weight gain and an initial under-prediction of $\mathrm{Cr}$ deposition downstream of the $704{ }^{\circ} \mathrm{C}$ location. The large difference between the simulated and experimental weight changes at $566{ }^{\circ} \mathrm{C}$ might be due to the overestimation of the deposition rate. The deposition rate, in this case, is assumed to be dependent on mass transfer of $\mathrm{Cr}$ to surfaces in that segment (see Section 6.1). In reality, the deposition rate may be dependent on the chemical rate of the inverse corrosion reaction (the inverse of Eq. (25)). This rate is unknown. If the actual kinetics of the deposition reaction are slower than the rate of mass transfer, then compared to reality, the TRIDENT simulation will calculate higher rates of deposition. This would result in locally higher weight gain, such as was predicted by TRIDENT at $566{ }^{\circ} \mathrm{C}$. 


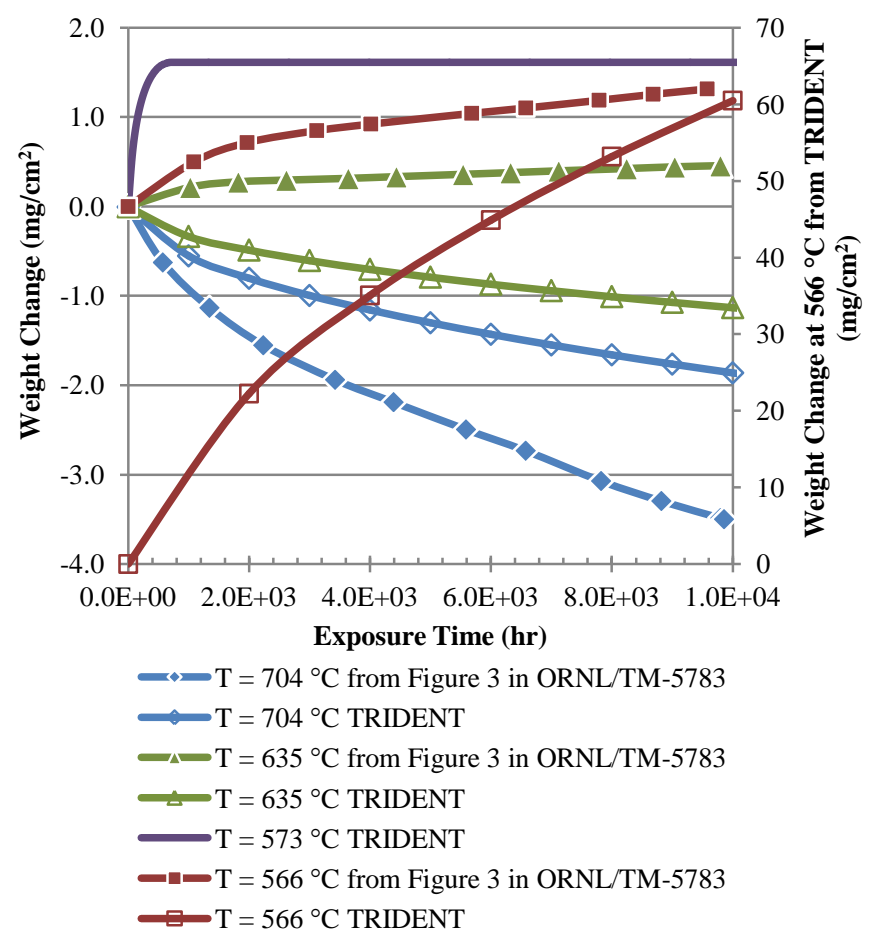

Fig. 12. Measured and calculated net weight change within Loop 21A as a function of exposure time. Measurement data from (Keiser, 1977).

\section{Conclusions}

Fluoride salt-cooled high temperature reactors (FHRs) using flibe (or other salts containing LiF and/or $\mathrm{BeF}_{2}$ ) will experience tritium production via neutron transmutation. A unique model of TRItium Diffusion Evolution and Transport (TRIDENT) was developed and benchmarked (Stempien, 2015). TRIDENT is the first such model to integrate the effects of tritium transport, reactor coolant chemistry, and corrosion phenomena. While TRIDENT was developed for FHRs, it can be easily extended for use with MSRs. The important dependencies captured in TRIDENT and the results of benchmarking comparisons were highlighted. Part II of this article will present the results of TRIDENT simulations in a prototypical FHR.

TRIDENT accounts for the time-dependent production rate of tritium in flibe in the reactor core. TRIDENT connects the chemical form of tritium ( $\mathrm{TF}$ versus $\mathrm{T}_{2}$ ) to the chemical redox potential in the salt. Tritium transport throughout the reactor system (including adsorption on graphite and permeation through heat exchangers) is modeled in TRIDENT. Tritium diffusion through the heat exchanger walls is treated by a finite difference diffusion method in the metal. The boundary conditions are specified by enforcing an equilibrium (determined by Henry's law in the salt and Sieverts' law in the metal) at the salt-metal boundary and by conserving the mass flux to the metal surface with the mass flux into the metal surface.

While data from a forced-convection polythermal loop of molten salt containing tritium do not exist for comparison, TRIDENT can be compared to data from static salt diffusion tests. Two such 
tests were used for benchmarking here. One test involves tritium diffusion through Ni and flibe, and the other test involves tritium diffusion through Ni and flinak. In each case, TRIDENT matched the transient and steady-state behavior of these tritium diffusion experiments.

In addition to controlling the chemical form of tritium, the chemical redox potential also determines the extent of corrosion. Selective chromium oxidation, corrosion product transport in the salt, and corrosion product deposition on reactor surfaces are all captured in TRIDENT. Corrosion of metals is simulated by considering the solid-state diffusion of chromium within the base metal and the thermodynamic equilibria along the coolant loop. The corrosion model in TRIDENT was compared against the natural convection flow-loop experiments at ORNL from the 1960s and early 1970s which used MSRE fuel salt containing $\mathrm{UF}_{4}$. Despite the lack of data required by TRIDENT for modeling these natural convection loops, some reasonable results were obtained. The TRIDENTsimulated corrosion rates follow the experimentally observed dependence on the square root of the product of the solid-state $\mathrm{Cr}$ diffusion coefficient with time. Additionally, the TRIDENT model shows mass transfer of corrosion products from the hot to the cold leg (as was observed in the experiments loop experiments at ORNL). Improvements to the corrosion model must recognize that bulk diffusion and grain boundary diffusion of $\mathrm{Cr}$ can be related due to the existence of 3D networks of grain boundaries in real materials. Flow loop corrosion experiments may be required along with an investigation of the deposition kinetics (inverse of the corrosion reaction) in order to improve the corrosion model. Mass transport and deposition of $\mathrm{Cr}$ on austenitic stainless steel piping may result in locally higher $\mathrm{Cr}$ concentrations, which might be sufficient to stabilize the low-carbon ferrite phase. Rapid diffusion of $\mathrm{Cr}$ into the stainless steel from the surface may mitigate this occurrence; however, this is another effect to consider in future work.

\section{Acknowledgments}

This work was made possible by the Department of Energy (DOE) Nuclear Energy University Program (NEUP), which awarded a 3-year Integrated Research Project (IRP) to MIT and its partners at the University of California-Berkeley and the University of Wisconsin-Madison for research and development of the fluoride-salt-cooled high-temperature reactor (FHR).

\section{References}

Abuzaid, W., Oral, A., Sehitoglu, H., Lambros, J., Maier, H.J., 2013. Fatigue crack initiation in Hastelloy X - the role of boundaries. Fatigue Fract Engng Mater Struct 36, 809-826. doi:10.1111/ffe. 12048

Anderl, R.A., Fukada, S., Smolik, G.R., Pawelko, R.J., Schuetz, S.T., Sharpe, J.P., Merrill, B.J., Petti, D.A., Nishimura, H., Terai, T., Tanaka, S., 2004. Deuterium/tritium behavior in Flibe and Flibe-facing materials. Journal of Nuclear Materials 329-333, Part B, 1327-1331. doi:10.1016/j.jnucmat.2004.04.220

Andreades, C., Cisneros, A.T., Choi, J.K., Chong, Y.K., Fratoni, M., Hong, S., Huddar, L.R., Huff, K.D., Laufer, M.R., Munk, M., Scarlat, R.O., Zweibaum, N., Greenspan, E., Peterson, P.F., 2014. Technical Description of the "Mark 1" Pebble-Bed Fluoride-Salt-Cooled High- 
Temperature Reactor (PB-FHR) Power Plant (No. UCBTH-14-002). University of California-Berkeley, University of California, Berkeley.

Anno, J.N., Walowit, J.A., 1971. Analysis of Corrosion of Stainless Steel in a Sodium and High Radiation Environment. Nuc. Tech. 10, 67-75.

Atsumi, H., Tokura, S., Miyake, M., 1988. Absorption and desorption of deuterium on graphite at elevated temperatures. Journal of Nuclear Materials 155-157, Part 1, 241-245. doi:10.1016/0022-3115(88)90247-4

Baes Jr., C.F., 1969. Symposium on Reprocessing of Nuclear Fuels: The Chemistry and Thermodynamics of Molten Salt Reactor Fuels. Nuclear Metallurgy 15, 617-644.

Beneš, O., Konings, R.J.M., 2012. 3.13 - Molten Salt Reactor Fuel and Coolant, in: Comprehensive Nuclear Materials. Elsevier, Oxford, pp. 359-389.

Briggs, R.B., 1971. Tritium in Molten-Salt Reactors. Reactor Technology 14, 335.

Briggs, R.B., Nestor, C.W., 1975. A Method for calculating the steady state distribution of tritium in a molten salt breeder reactor plant (No. ORNL-TM-4804). Oak Ridge National Laboratory.

Calderoni, P., Sharpe, P., Hara, M., Oya, Y., 2008. Measurement of tritium permeation in flibe (2LiF-BeF2). Fusion Engineering and Design 83, 1331-1334. doi:10.1016/j.fusengdes.2008.05.016

Calderoni, P., Sharpe, P., Nishimura, H., Terai, T., 2009. Control of molten salt corrosion of fusion structural materials by metallic beryllium. Journal of Nuclear Materials 386-388, 1102-1106. doi:10.1016/j.jnucmat.2008.12.292

Cantor, S., Grimes, W.R., 1974. Fused-Salt Corrosion and Its Control in Fusion Reactors. NT 22, $120-126$.

Causey, R.A., Karnesky, R.A., San Marchi, C., 2012. 4.16 - Tritium Barriers and Tritium Diffusion in Fusion Reactors, in: Konings, R.J.M. (Ed.), Comprehensive Nuclear Materials. Elsevier, Oxford, pp. 511-549.

Cisneros, A.T., 2013. Pebble Bed Reactors Design Optimization Methods and their Application to the Pebble Bed Fluoride Salt Cooled High Temperature Reactor (PB-FHR) (PhD). University of California, Berkeley.

Del Cul, G.D., Williams, D.F., Toth, L.M., Caja, J., 2002. Redox Potential of Novel Electrochemical Buffers Useful for Corrosion Prevention in Molten Fluorides, in: Proceedings of the Thirteenth International Symposium on Molten Salts. Philadelphia, PA.

Evans III, R.B., DeVan, J.H., Watson, G.M., 1961. Self-Diffusion of Chromium in Nickel-Base Alloys (No. ORNL-2982). Oak Ridge National Laboratory, Oak Ridge National Laboratory.

Evans III, R.B., Koger, J.W., DeVan, J.H., 1971. Corrosion in polythermal loop systems II. A solidstate diffusion mechanism with and without liquid film effects (No. ORNL-4575, Vol 2). Oak Ridge National Laboratory, Oak Ridge National Laboratory.

Field, P.E., Shaffer, J.H., 1967. The solubilities of hydrogen fluoride and deuterium fluoride in molten fluorides. J. Phys. Chem. 71, 3218-3222. doi:10.1021/j100869a013

Forsberg, C., Peterson, P.F., Pickard, P.S., 2003. Molten-Salt-Cooled Advanced High-Temperature Reactor for Production of Hydrogen and Electricity. Nuclear Technology 144, 289-302.

Forsberg, C.W., Curtis, D., Stempien, J., MacDonald, R., Peterson, P., 2014a. Fluoride-Salt-Cooled High-Temperature Reactor (FHR) Commercial Basis and Commercialization Strategy (No. MIT-ANP-TF-153). Center for Advanced Nuclear Energy Systems, Massachusetts Institute of Technology.

Forsberg, C.W., Hu, L., Peterson, P.F., Sridharan, K., 2014b. Fluoride-Salt-Cooled High Temperature Reactor (FHR) for Power and Process Heat Final Project Report (No. MITANP-TR-157). Center for Advanced Nuclear Energy Systems, Massachusetts Institute of Technology. 
Forsberg, C.W., Hu, L., Peterson, P.F., Sridharan, K., 2013. Fluoride-Salt-Cooled High-Temperature Reactors (FHRs) for Base-Load and Peak Electricity, Grid Stabilization, and Process Heat (No. MIT-ANP-TR-147). Massachusetts Institute of Technology: Center for Advanced Energy Systems.

Fukada, S., Anderl, R.A., Hatano, Y., Schuetz, S.T., Pawelko, R.J., Petti, D.A., Smolik, G.R., Terai, T., Nishikawa, M., Tanaka, S., Sagara, A., 2002. Initial studies of tritium behavior in flibe and flibe-facing material. Fusion Engineering and Design 61-62, 783-788. doi:10.1016/S0920-3796(02)00204-1

Fukada, S., Anderl, R.A., Sagara, A., Nishikawa, M., 2005. Diffusion Coefficient of Tritium Through Molten Salt Flibe and Rate of Tritium Leak from Fusion Reactor System. FST 48, 666-669.

Fukada, S., Edao, Y., Katekari, K., Okitsu, H., Hatachi, Y., Okada, M., Tamari, K., 2012. Tritium Recovery from Liquid Blanket Systems for Fusion Reactor. Transactions of Fusion Science and Technology 61, 58-63.

Fukada, S., Morisaki, A., 2006. Hydrogen permeability through a mixed molten salt of LiF, NaF and KF (Flinak) as a heat-transfer fluid. Journal of Nuclear Materials 358, 235-242. doi:10.1016/j.jnucmat.2006.07.011

Fukada, S., Morisaki, A., Sagara, A., Terai, T., 2006. Control of tritium in FFHR-2 self-cooled Flibe blanket. Fusion Engineering and Design 81, 477-483. doi:10.1016/j.fusengdes.2005.09.017

Gehlbach, R.E., McCoy, H.E., 1968. Phase Instability in Hastelloy N, in: International Symposium on Structural Stability in Superalloys. Seven Springs, PA, pp. 346-366.

General Atomics, 2009. Engineering Services for the Next Generation Nuclear Plant (NGNP) with Hydrogen Production - Technical Basis for NGNP Fuel Performance and Quality Requirements (GA Project 30302) (No. 911168). General Atomics.

Haubenreich, P.N., Engel, J.., Prince, B.E., Claiborne, H.C., 1964. MSRE Design and Operations Report Part III. Nuclear Analysis (No. ORNL-TM-730). Oak Ridge National Laboratory, Oak Ridge National Laboratory.

Haubenreich, P.N., Engel, J.R., 1970. Experience with the Molten-Salt Reactor Experiment. Nucl. Appl. Tech. 8, 118-136.

Holcomb, D.E., Flanagan, G.F., Mays, G.T., Pointer, W.D., Robb, K.R., Yoder, Jr., G.L., 2013. Fluoride Salt-Cooled High-Temperature Reactor Technology Development and Demonstration Roadmap (No. ORNL/TM-2013/401). Oak Ridge National Laboratory, Oak Ridge National Laboratory.

Hollenberg, G.., Simonen, E.., Kalinin, G., Terlain, A., 1995. Tritium/hydrogen barrier development. Fusion Engineering and Design 28, 190-208. doi:10.1016/0920-3796(95)90039-X

Ignatiev, V., Surenkov, A., 2012. 5.10 - Material Performance in Molten Salts, in: Rudy J.M. Konings (Ed.), Comprehensive Nuclear Materials. Elsevier, Oxford, pp. 221-250.

Ingersoll, D.T., Forsberg, C., Ott, L.J., Williams, D.F., Renier, J.P., Wilson, D.F., Ball, S.J., Reid, L., Corwin, W.R., Del Cul, G.D., Peterson, P.F., Zhao, H., Pickard, P.S., Parma, E.J., 2004. Status of Preconceptual Design of the Advanced High-Temperature Reactor (AHTR) (No. ORNL/TM-2004/104). Oak Ridge National Laboratory.

Katsuta, H., Furukawa, K., 1981. Hydrogen and Deuterium Transport through Type 304 Stainless Steel at Elevated Temperatures. Journal of Nuclear Science and Technology 18, 143-151. doi:10.1080/18811248.1981.9733235

Keiser, J.R., 1977. Compatibility Studies of Potential Molten-Salt Breeder Reactor Materials in Molten Fluoride Salts (No. ORNL/TM-5783). Oak Ridge National Laboratory.

Keiser, J.R., DeVan, J.H., Manning, D.L., 1977. The Corrosion Resistance of Type 316 Stainless Steel to Li2BeF4 (No. ORNL/TM-5782). Oak Ridge National Laboratory. 
Kishimoto, N., Tanabe, T., Suzuki, T., Yoshida, H., 1985. Hydrogen diffusion and solution at high temperatures in 316L stainless steel and nickel-base heat-resistant alloys. Journal of Nuclear Materials 127, 1-9.

Koger, J.W., 1972a. Evaluation of Hastelloy N Alloys After Nine Years Exposure to Both a Molten Fluorided Salt and Air at Temperatures from 700 to 560 C (No. ORNL-TM-4189). Oak Ridge National Laboratory.

Koger, J.W., 1972b. Alloy Compatibility with LiF-BeF2 Salts Containing ThF4 and UF4 (No. ORNL-TM-4286). Oak Ridge National Laboratory.

Kondo, M., Nagasaka, T., Sagara, A., Noda, N., Muroga, T., Xu, Q., Nagura, M., Suzuki, A., Terai, T., 2009a. Metallurgical study on corrosion of austenitic steels in molten salt LiF-BeF2 (Flibe). Journal of Nuclear Materials 386-388, 685-688. doi:10.1016/j.jnucmat.2008.12.317

Kondo, M., Nagasaka, T., Xu, Q., Muroga, T., Sagara, A., Noda, N., Ninomiya, D., Nagura, M., Suzuki, A., Terai, T., Fujii, N., 2009b. Corrosion characteristics of reduced activation ferritic steel, JLF-1 (8.92Cr-2W) in molten salts Flibe and Flinak. Fusion Engineering and Design 84, 1081-1085. doi:10.1016/j.fusengdes.2009.02.046

MacPherson, H.G., 1985. The Molten Salt Reactor Adventure. NSE 90, 374-380.

Malinauskas, A.P., Richardson, D.M., 1974. The Solubilities of Hydrogen, Deuterium, and Helium in Molten Li2BeF4. Ind. Eng. Chem. Fund. 13, 242-245. doi:10.1021/i160051a015

Management of Waste Containing Tritium and Carbon-14 (No. Technical Reports Series No. 421), 2004. . International Atomic Energy Agency, Vienna.

McNeese, L.E., 1974. Program Plan for Development of Molten-Salt Breeder Reactors (No. ORNL5018). Oak Ridge National Laboratory.

Mizouchi, M., Yamazaki, Y., Iijima, Y., Arioka, K., 2004. Low Temperature Grain Boundary Diffusion of Chromium in SUS 316 and 316L Stainless Steels. Materials Transactions 45, 2945-2950.

Oh, C.H., Kim, E.S., 2009. Development and Verification of Tritium Analyses Code for a Very High Temperature Reactor (No. INL/EXT-09-16743). Idaho National Laboratory.

Olander, D., 2002. Redox condition in molten fluoride salts: Definition and control. Journal of Nuclear Materials 300, 270-272. doi:10.1016/S0022-3115(01)00742-5

Oya, Y., Kobayashi, M., Osuo, J., Suzuki, M., Hamada, A., Matsuoka, K., Hatano, Y., Matsuyama, M., Hayashi, T., Yamanishi, T., Okuno, K., 2012. Effect of surface oxide layer on deuterium permeation behaviors through a type 316 stainless steel. Fusion Engineering and Design 87, 580-583. doi:10.1016/j.fusengdes.2012.01.025

Pruthi, D.D., Anand, M.S., Agarwala, R.P., 1977. Diffusion of chromium in Iconel-600. Journal of Nuclear Materials 64, 206-210.

Rosenthal, M.W., Briggs, R.B., Haubenreich, P.N., 1971. Molten-Salt Reactor Program Semiannual Progress Report (No. ORNL-4676). Oak Ridge National Laboratory, Oak Ridge National Laboratory.

Seader, J.D., Henley, E.J., Roper, D.K., 2010. Separation Process Principles, 3rd Edition, 3 edition. ed. John Wiley \& Sons, Inc.

Shaffer, J.H., 1971. Preparation and Handling of Salt Mixtures for the Molten Salt Reactor Experiment (No. ORNL-4616). Oak Ridge National Laboratory.

Shapiro, M.D., Reed, C.M., 1970. Removal of Tritium from the Molten Salt Breeder Reactor Fuel (No. ORNL-MIT-117). Oak Ridge National Laboratory, Oak Ridge National Laboratory.

Sohal, M.S., Ebner, M.A., Sabharwall, P., Sharpe, P., 2010. Engineering Database of Liquid Salt Thermophysical and Thermochemical Properties (No. INL/EXT-10-18297). Idaho National Laboratory, Idaho National Laboratory. 
Stempien, J.D., 2015. Tritium Transport, Corrosion, and Fuel Performance Modeling in the Fluoride Salt-Cooled High-Temperature Reactor (FHR) (PhD Thesis). Massachusetts Institute of Technology, Cambridge, MA.

Suzuki, A., Terai, T., Tanaka, S., 2000. Tritium release behavior from Li2BeF4 molten salt by permeation through structural materials. Fusion Engineering and Design 51-52, 863-868. doi:10.1016/S0920-3796(00)00233-7

Suzuki, A., Terai, T., Tanaka, S., 1998. Change of tritium species in Li2BeF4 molten salt breeder under neutron irradiation at elevated temperature. Journal of Nuclear Materials 258-263, Part 1, 519-524. doi:10.1016/S0022-3115(98)00423-1

Tanabe, T., Yamanishi, Y., Sawada, K., Imoto, S., 1984. Hydrogen Transport in Stainless Steels. Journal of Nuclear Materials 122 \& 123, 1568-1572.

Thoma, R.E., 1971. Chemical Aspects of MSRE Operations (No. ORNL-4658). Oak Ridge National Laboratory, Oak Ridge National Laboratory.

Toth, L.M., Cul, G.D.D., Dai, S., Metcalf, D.H., 1995. Molten fluoride fuel salt chemistry, in: AIP Conference Proceedings. Presented at the The international conference on accelerator-driven transmutation technologies and applications, AIP Publishing, pp. 617-626. doi:10.1063/1.49142

Wang, L., Stuckert, N.R., Yang, R.T., 2011. Unique Hydrogen Adsorption Properties of Graphene. AIChE Journal 57, 2902-2908.

Wichner, R.P., Dyer, F.., 1979. Distribution and Transport of Tritium in the Peach Bottom HTGR (No. ORNL-5497). Oak Ridge National Laboratory.

Williams, D.F., Toth, L.M., Clarno, K.T., 2006. Assessment of Candidate Molten Salt Coolants for the Advanced High-Temperature Reactor (AHTR) (No. ORNL/TM-2006/12). Oak Ridge National Laboratory, Oak Ridge National Laboratory.

Zhang, J., Hosemann, P., Maloy, S., 2010. Models of liquid metal corrosion. Journal of Nuclear Materials 404, 82-96. doi:10.1016/j.jnucmat.2010.05.024 


\title{
An Integrated Model of Tritium Transport and Corrosion in Fluoride Salt- Cooled High-Temperature Reactors (FHRs) - Part I: Theory and Benchmarking
}

\author{
John D. Stempien*, Ronald G. Ballinger, and Charles W. Forsberg \\ Department of Nuclear Science and Engineering, Massachusetts Institute of Technology, \\ 77 Massachusetts Ave, Cambridge, MA 02139
}

\section{References}

Abuzaid, W., Oral, A., Sehitoglu, H., Lambros, J., Maier, H.J., 2013. Fatigue crack initiation in Hastelloy X - the role of boundaries. Fatigue Fract Engng Mater Struct 36, 809-826. doi:10.1111/ffe. 12048

Anderl, R.A., Fukada, S., Smolik, G.R., Pawelko, R.J., Schuetz, S.T., Sharpe, J.P., Merrill, B.J., Petti, D.A., Nishimura, H., Terai, T., Tanaka, S., 2004. Deuterium/tritium behavior in Flibe and Flibe-facing materials. Journal of Nuclear Materials 329-333, Part B, 1327-1331. doi:10.1016/j.jnucmat.2004.04.220

Andreades, C., Cisneros, A.T., Choi, J.K., Chong, Y.K., Fratoni, M., Hong, S., Huddar, L.R., Huff, K.D., Laufer, M.R., Munk, M., Scarlat, R.O., Zweibaum, N., Greenspan, E., Peterson, P.F., 2014. Technical Description of the "Mark 1" Pebble-Bed Fluoride-Salt-Cooled HighTemperature Reactor (PB-FHR) Power Plant (No. UCBTH-14-002). University of California-Berkeley, University of California, Berkeley.

Anno, J.N., Walowit, J.A., 1971. Analysis of Corrosion of Stainless Steel in a Sodium and High Radiation Environment. Nuc. Tech. 10, 67-75.

Atsumi, H., Tokura, S., Miyake, M., 1988. Absorption and desorption of deuterium on graphite at elevated temperatures. Journal of Nuclear Materials 155-157, Part 1, 241-245. doi:10.1016/0022-3115(88)90247-4

Baes Jr., C.F., 1969. Symposium on Reprocessing of Nuclear Fuels: The Chemistry and Thermodynamics of Molten Salt Reactor Fuels. Nuclear Metallurgy 15, 617-644.

Beneš, O., Konings, R.J.M., 2012. 3.13 - Molten Salt Reactor Fuel and Coolant, in: Comprehensive Nuclear Materials. Elsevier, Oxford, pp. 359-389.

Briggs, R.B., 1971. Tritium in Molten-Salt Reactors. Reactor Technology 14, 335.

Briggs, R.B., Nestor, C.W., 1975. A Method for calculating the steady state distribution of tritium in a molten salt breeder reactor plant (No. ORNL-TM-4804). Oak Ridge National Laboratory.

Calderoni, P., Sharpe, P., Hara, M., Oya, Y., 2008. Measurement of tritium permeation in flibe (2LiF-BeF2). Fusion Engineering and Design 83, 1331-1334. doi:10.1016/j.fusengdes.2008.05.016

Calderoni, P., Sharpe, P., Nishimura, H., Terai, T., 2009. Control of molten salt corrosion of fusion structural materials by metallic beryllium. Journal of Nuclear Materials 386-388, 1102-1106. doi:10.1016/j.jnucmat.2008.12.292

Cantor, S., Grimes, W.R., 1974. Fused-Salt Corrosion and Its Control in Fusion Reactors. NT 22, $120-126$.

Causey, R.A., Karnesky, R.A., San Marchi, C., 2012. 4.16 - Tritium Barriers and Tritium Diffusion in Fusion Reactors, in: Konings, R.J.M. (Ed.), Comprehensive Nuclear Materials. Elsevier, Oxford, pp. 511-549.

Cisneros, A.T., 2013. Pebble Bed Reactors Design Optimization Methods and their Application to the Pebble Bed Fluoride Salt Cooled High Temperature Reactor (PB-FHR) (PhD). University of California, Berkeley. 
Del Cul, G.D., Williams, D.F., Toth, L.M., Caja, J., 2002. Redox Potential of Novel Electrochemical Buffers Useful for Corrosion Prevention in Molten Fluorides, in: Proceedings of the Thirteenth International Symposium on Molten Salts. Philadelphia, PA.

Evans III, R.B., DeVan, J.H., Watson, G.M., 1961. Self-Diffusion of Chromium in Nickel-Base Alloys (No. ORNL-2982). Oak Ridge National Laboratory, Oak Ridge National Laboratory.

Evans III, R.B., Koger, J.W., DeVan, J.H., 1971. Corrosion in polythermal loop systems II. A solidstate diffusion mechanism with and without liquid film effects (No. ORNL-4575, Vol 2). Oak Ridge National Laboratory, Oak Ridge National Laboratory.

Field, P.E., Shaffer, J.H., 1967. The solubilities of hydrogen fluoride and deuterium fluoride in molten fluorides. J. Phys. Chem. 71, 3218-3222. doi:10.1021/j100869a013

Forsberg, C., Peterson, P.F., Pickard, P.S., 2003. Molten-Salt-Cooled Advanced High-Temperature Reactor for Production of Hydrogen and Electricity. Nuclear Technology 144, 289-302.

Forsberg, C.W., Curtis, D., Stempien, J., MacDonald, R., Peterson, P., 2014a. Fluoride-Salt-Cooled High-Temperature Reactor (FHR) Commercial Basis and Commercialization Strategy (No. MIT-ANP-TF-153). Center for Advanced Nuclear Energy Systems, Massachusetts Institute of Technology.

Forsberg, C.W., Hu, L., Peterson, P.F., Sridharan, K., 2014b. Fluoride-Salt-Cooled High Temperature Reactor (FHR) for Power and Process Heat Final Project Report (No. MITANP-TR-157). Center for Advanced Nuclear Energy Systems, Massachusetts Institute of Technology.

Forsberg, C.W., Hu, L., Peterson, P.F., Sridharan, K., 2013. Fluoride-Salt-Cooled High-Temperature Reactors (FHRs) for Base-Load and Peak Electricity, Grid Stabilization, and Process Heat (No. MIT-ANP-TR-147). Massachusetts Institute of Technology: Center for Advanced Energy Systems.

Fukada, S., Anderl, R.A., Hatano, Y., Schuetz, S.T., Pawelko, R.J., Petti, D.A., Smolik, G.R., Terai, T., Nishikawa, M., Tanaka, S., Sagara, A., 2002. Initial studies of tritium behavior in flibe and flibe-facing material. Fusion Engineering and Design 61-62, 783-788. doi:10.1016/S0920-3796(02)00204-1

Fukada, S., Anderl, R.A., Sagara, A., Nishikawa, M., 2005. Diffusion Coefficient of Tritium Through Molten Salt Flibe and Rate of Tritium Leak from Fusion Reactor System. FST 48, 666-669.

Fukada, S., Edao, Y., Katekari, K., Okitsu, H., Hatachi, Y., Okada, M., Tamari, K., 2012. Tritium Recovery from Liquid Blanket Systems for Fusion Reactor. Transactions of Fusion Science and Technology 61, 58-63.

Fukada, S., Morisaki, A., 2006. Hydrogen permeability through a mixed molten salt of LiF, NaF and KF (Flinak) as a heat-transfer fluid. Journal of Nuclear Materials 358, 235-242. doi:10.1016/j.jnucmat.2006.07.011

Fukada, S., Morisaki, A., Sagara, A., Terai, T., 2006. Control of tritium in FFHR-2 self-cooled Flibe blanket. Fusion Engineering and Design 81, 477-483. doi:10.1016/j.fusengdes.2005.09.017

Gehlbach, R.E., McCoy, H.E., 1968. Phase Instability in Hastelloy N, in: International Symposium on Structural Stability in Superalloys. Seven Springs, PA, pp. 346-366.

General Atomics, 2009. Engineering Services for the Next Generation Nuclear Plant (NGNP) with Hydrogen Production - Technical Basis for NGNP Fuel Performance and Quality Requirements (GA Project 30302) (No. 911168). General Atomics.

Haubenreich, P.N., Engel, J.., Prince, B.E., Claiborne, H.C., 1964. MSRE Design and Operations Report Part III. Nuclear Analysis (No. ORNL-TM-730). Oak Ridge National Laboratory, Oak Ridge National Laboratory.

Haubenreich, P.N., Engel, J.R., 1970. Experience with the Molten-Salt Reactor Experiment. Nucl. Appl. Tech. 8, 118-136. 
Holcomb, D.E., Flanagan, G.F., Mays, G.T., Pointer, W.D., Robb, K.R., Yoder, Jr., G.L., 2013. Fluoride Salt-Cooled High-Temperature Reactor Technology Development and Demonstration Roadmap (No. ORNL/TM-2013/401). Oak Ridge National Laboratory, Oak Ridge National Laboratory.

Hollenberg, G.., Simonen, E.., Kalinin, G., Terlain, A., 1995. Tritium/hydrogen barrier development. Fusion Engineering and Design 28, 190-208. doi:10.1016/0920-3796(95)90039-X

Ignatiev, V., Surenkov, A., 2012. 5.10 - Material Performance in Molten Salts, in: Rudy J.M. Konings (Ed.), Comprehensive Nuclear Materials. Elsevier, Oxford, pp. 221-250.

Ingersoll, D.T., Forsberg, C., Ott, L.J., Williams, D.F., Renier, J.P., Wilson, D.F., Ball, S.J., Reid, L., Corwin, W.R., Del Cul, G.D., Peterson, P.F., Zhao, H., Pickard, P.S., Parma, E.J., 2004. Status of Preconceptual Design of the Advanced High-Temperature Reactor (AHTR) (No. ORNL/TM-2004/104). Oak Ridge National Laboratory.

Katsuta, H., Furukawa, K., 1981. Hydrogen and Deuterium Transport through Type 304 Stainless Steel at Elevated Temperatures. Journal of Nuclear Science and Technology 18, 143-151. doi:10.1080/18811248.1981.9733235

Keiser, J.R., 1977. Compatibility Studies of Potential Molten-Salt Breeder Reactor Materials in Molten Fluoride Salts (No. ORNL/TM-5783). Oak Ridge National Laboratory.

Keiser, J.R., DeVan, J.H., Manning, D.L., 1977. The Corrosion Resistance of Type 316 Stainless Steel to Li2BeF4 (No. ORNL/TM-5782). Oak Ridge National Laboratory.

Kishimoto, N., Tanabe, T., Suzuki, T., Yoshida, H., 1985. Hydrogen diffusion and solution at high temperatures in 316L stainless steel and nickel-base heat-resistant alloys. Journal of Nuclear Materials 127, 1-9.

Koger, J.W., 1972a. Evaluation of Hastelloy N Alloys After Nine Years Exposure to Both a Molten Fluorided Salt and Air at Temperatures from 700 to 560 C (No. ORNL-TM-4189). Oak Ridge National Laboratory.

Koger, J.W., 1972b. Alloy Compatibility with LiF-BeF2 Salts Containing ThF4 and UF4 (No. ORNL-TM-4286). Oak Ridge National Laboratory.

Kondo, M., Nagasaka, T., Sagara, A., Noda, N., Muroga, T., Xu, Q., Nagura, M., Suzuki, A., Terai, T., 2009a. Metallurgical study on corrosion of austenitic steels in molten salt LiF-BeF2 (Flibe). Journal of Nuclear Materials 386-388, 685-688. doi:10.1016/j.jnucmat.2008.12.317

Kondo, M., Nagasaka, T., Xu, Q., Muroga, T., Sagara, A., Noda, N., Ninomiya, D., Nagura, M., Suzuki, A., Terai, T., Fujii, N., 2009b. Corrosion characteristics of reduced activation ferritic steel, JLF-1 (8.92Cr-2W) in molten salts Flibe and Flinak. Fusion Engineering and Design 84, 1081-1085. doi:10.1016/j.fusengdes.2009.02.046

MacPherson, H.G., 1985. The Molten Salt Reactor Adventure. NSE 90, 374-380.

Malinauskas, A.P., Richardson, D.M., 1974. The Solubilities of Hydrogen, Deuterium, and Helium in Molten Li2BeF4. Ind. Eng. Chem. Fund. 13, 242-245. doi:10.1021/i160051a015

Management of Waste Containing Tritium and Carbon-14 (No. Technical Reports Series No. 421), 2004. . International Atomic Energy Agency, Vienna.

McNeese, L.E., 1974. Program Plan for Development of Molten-Salt Breeder Reactors (No. ORNL5018). Oak Ridge National Laboratory.

Mizouchi, M., Yamazaki, Y., Iijima, Y., Arioka, K., 2004. Low Temperature Grain Boundary Diffusion of Chromium in SUS 316 and 316L Stainless Steels. Materials Transactions 45, 2945-2950.

Oh, C.H., Kim, E.S., 2009. Development and Verification of Tritium Analyses Code for a Very High Temperature Reactor (No. INL/EXT-09-16743). Idaho National Laboratory.

Olander, D., 2002. Redox condition in molten fluoride salts: Definition and control. Journal of Nuclear Materials 300, 270-272. doi:10.1016/S0022-3115(01)00742-5 
Oya, Y., Kobayashi, M., Osuo, J., Suzuki, M., Hamada, A., Matsuoka, K., Hatano, Y., Matsuyama, M., Hayashi, T., Yamanishi, T., Okuno, K., 2012. Effect of surface oxide layer on deuterium permeation behaviors through a type 316 stainless steel. Fusion Engineering and Design 87, 580-583. doi:10.1016/j.fusengdes.2012.01.025

Pruthi, D.D., Anand, M.S., Agarwala, R.P., 1977. Diffusion of chromium in Iconel-600. Journal of Nuclear Materials 64, 206-210.

Rosenthal, M.W., Briggs, R.B., Haubenreich, P.N., 1971. Molten-Salt Reactor Program Semiannual Progress Report (No. ORNL-4676). Oak Ridge National Laboratory, Oak Ridge National Laboratory.

Seader, J.D., Henley, E.J., Roper, D.K., 2010. Separation Process Principles, 3rd Edition, 3 edition. ed. John Wiley \& Sons, Inc.

Shaffer, J.H., 1971. Preparation and Handling of Salt Mixtures for the Molten Salt Reactor Experiment (No. ORNL-4616). Oak Ridge National Laboratory.

Shapiro, M.D., Reed, C.M., 1970. Removal of Tritium from the Molten Salt Breeder Reactor Fuel (No. ORNL-MIT-117). Oak Ridge National Laboratory, Oak Ridge National Laboratory.

Sohal, M.S., Ebner, M.A., Sabharwall, P., Sharpe, P., 2010. Engineering Database of Liquid Salt Thermophysical and Thermochemical Properties (No. INL/EXT-10-18297). Idaho National Laboratory, Idaho National Laboratory.

Stempien, J.D., 2015. Tritium Transport, Corrosion, and Fuel Performance Modeling in the Fluoride Salt-Cooled High-Temperature Reactor (FHR) (PhD Thesis). Massachusetts Institute of Technology, Cambridge, MA.

Suzuki, A., Terai, T., Tanaka, S., 2000. Tritium release behavior from Li2BeF4 molten salt by permeation through structural materials. Fusion Engineering and Design 51-52, 863-868. doi:10.1016/S0920-3796(00)00233-7

Suzuki, A., Terai, T., Tanaka, S., 1998. Change of tritium species in Li2BeF4 molten salt breeder under neutron irradiation at elevated temperature. Journal of Nuclear Materials 258-263, Part 1, 519-524. doi:10.1016/S0022-3115(98)00423-1

Tanabe, T., Yamanishi, Y., Sawada, K., Imoto, S., 1984. Hydrogen Transport in Stainless Steels. Journal of Nuclear Materials 122 \& 123, 1568-1572.

Thoma, R.E., 1971. Chemical Aspects of MSRE Operations (No. ORNL-4658). Oak Ridge National Laboratory, Oak Ridge National Laboratory.

Toth, L.M., Cul, G.D.D., Dai, S., Metcalf, D.H., 1995. Molten fluoride fuel salt chemistry, in: AIP Conference Proceedings. Presented at the The international conference on accelerator-driven transmutation technologies and applications, AIP Publishing, pp. 617-626. doi:10.1063/1.49142

Wang, L., Stuckert, N.R., Yang, R.T., 2011. Unique Hydrogen Adsorption Properties of Graphene. AIChE Journal 57, 2902-2908.

Wichner, R.P., Dyer, F.., 1979. Distribution and Transport of Tritium in the Peach Bottom HTGR (No. ORNL-5497). Oak Ridge National Laboratory.

Williams, D.F., Toth, L.M., Clarno, K.T., 2006. Assessment of Candidate Molten Salt Coolants for the Advanced High-Temperature Reactor (AHTR) (No. ORNL/TM-2006/12). Oak Ridge National Laboratory, Oak Ridge National Laboratory.

Zhang, J., Hosemann, P., Maloy, S., 2010. Models of liquid metal corrosion. Journal of Nuclear Materials 404, 82-96. doi:10.1016/j.jnucmat.2010.05.024 
Figure 1

TF born from Transmutation

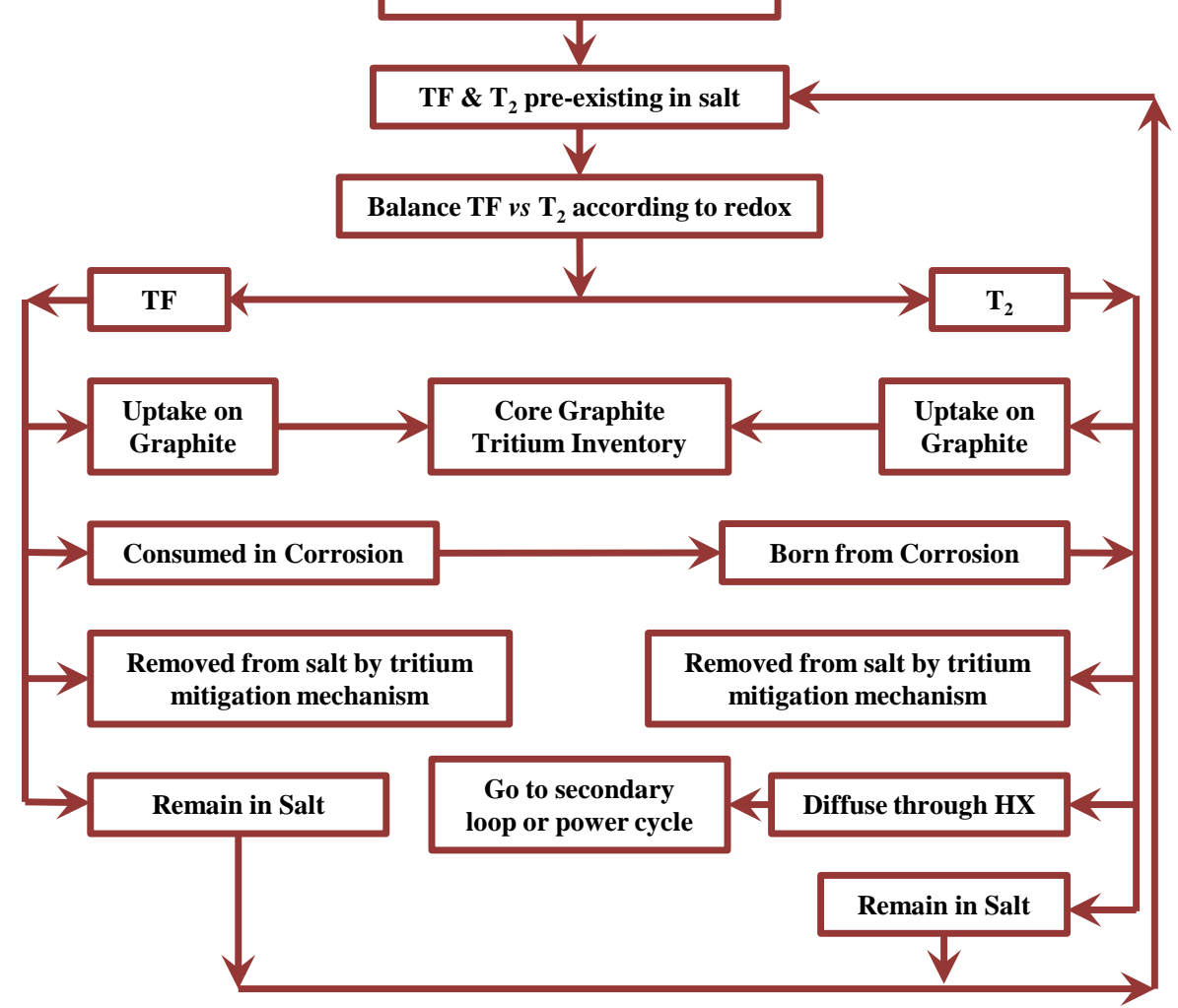




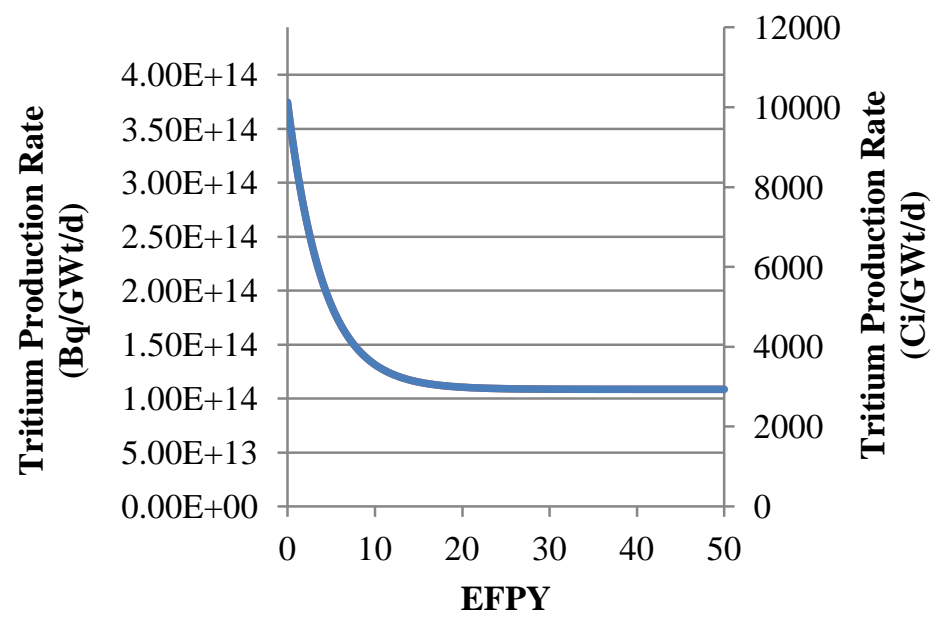

Figure 2 
Fig. 3

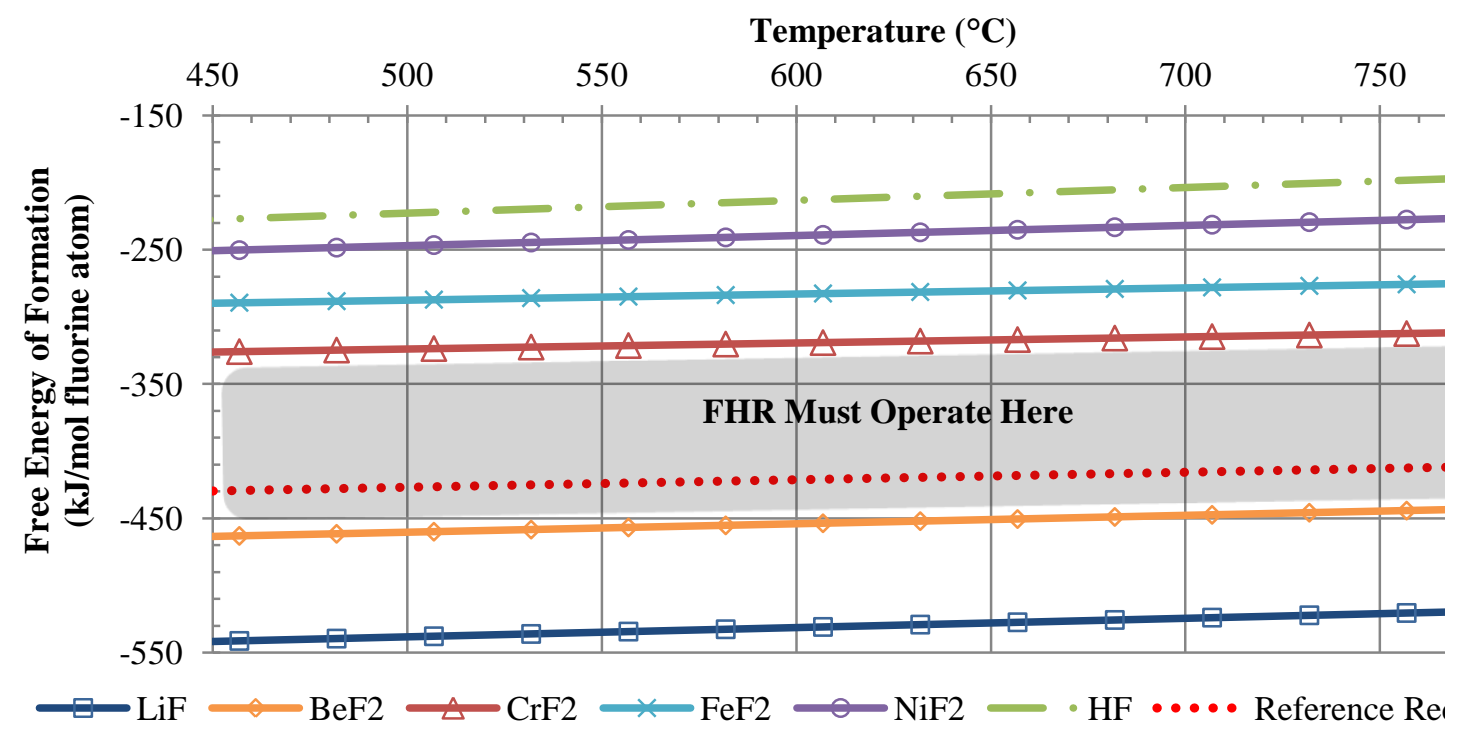




\section{Figure 4}

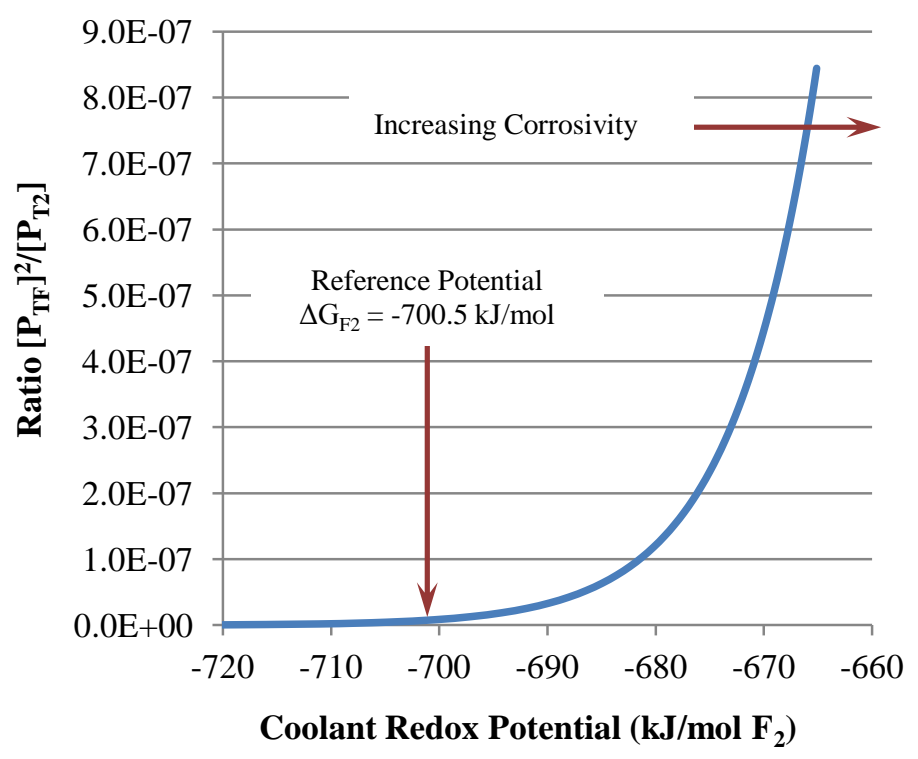

$\begin{array}{ccc}\text { Ratio of UF4:UF3 } & \text { Equivalent Fluorine Potential } & \\ 25 & -721.7660779 & \text { Ratio } \\ & (T F \wedge 2) / T 2 \\ 50 & -711.1255816 & 5.28 \mathrm{E}-10 \\ 75 & -704.9012902 & 2.11 \mathrm{E}-09 \\ 100 & -700.4850852 & 8.75 \mathrm{E}-09 \\ 125 & -697.0596104 & 1.32 \mathrm{E}-09 \\ 150 & -694.2607938 & 1.90 \mathrm{E}-08 \\ 175 & -691.894428 & 2.59 \mathrm{E}-08 \\ 200 & -689.8445888 & 3.38 \mathrm{E}-08 \\ 225 & -688.0365024 & 4.28 \mathrm{E}-08 \\ 250 & -686.419114 & 5.28 \mathrm{E}-08 \\ 275 & -684.9560083 & 6.39 \mathrm{E}-08 \\ 300 & -683.6202974 & 7.60 \mathrm{E}-08 \\ 325 & -682.3915625 & 8.92 \mathrm{E}-08 \\ 350 & -681.2539316 & 1.03 \mathrm{E}-07 \\ 375 & -680.1948227 & 1.19 \mathrm{E}-07 \\ 400 & -679.2040924 & 1.35 \mathrm{E}-07 \\ 425 & -678.2734443 & 1.53 \mathrm{E}-07 \\ 450 & -677.396006 & 1.71 \mathrm{E}-07 \\ 475 & -676.5660206 & 1.91 \mathrm{E}-07 \\ 500 & -675.7786177 & 2.11 \mathrm{E}-07 \\ 525 & -675.0296403 & 2.33 \mathrm{E}-07 \\ 550 & -674.3155119 & 2.55 \mathrm{E}-07 \\ 575 & -673.6331333 & 2.79 \mathrm{E}-07 \\ 600 & -672.979801 & 3.04 \mathrm{E}-07 \\ 625 & -672.3531429 & 3.30 \mathrm{E}-07 \\ 650 & -671.7510661 & 3.57 \mathrm{E}-07 \\ & -671.1717146 & 3.85 \mathrm{E}-07\end{array}$


Figure 5

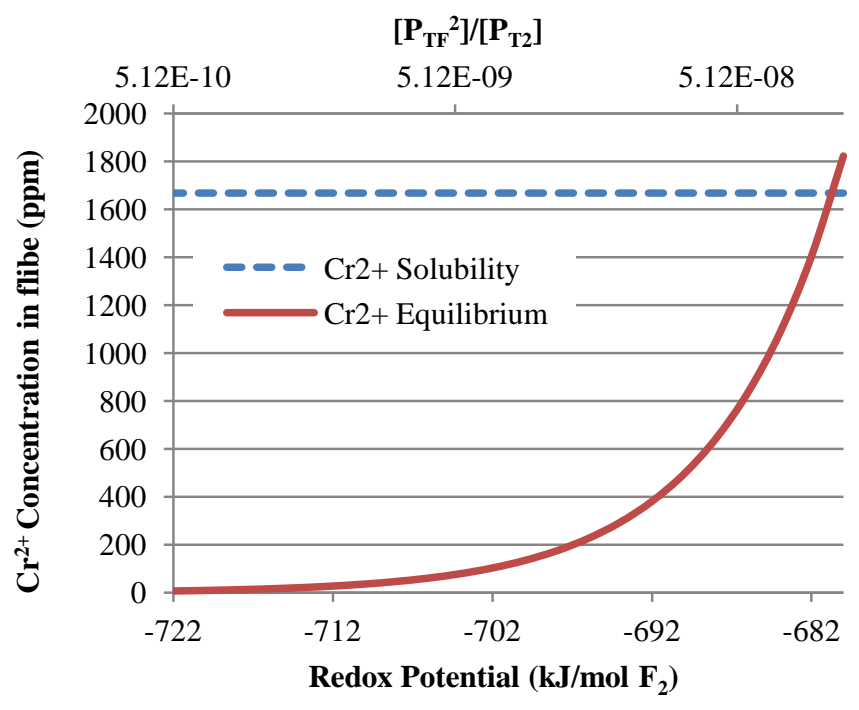

Equilibrium calculation of 316 SS ir Standalone calculation of equilibri Temp $=650 \mathrm{C}$

[Cr2+] vs Ri

Delta G F2 Ratio (TF^2 [Cr2+] vs Ri

$\begin{array}{rrr}-680 & 1.22 \mathrm{E}-07 & 1823.775 \\ -682 & 9.39 \mathrm{E}-08 & 1405.424 \\ -684 & 7.23 \mathrm{E}-08 & 1083.038 \\ -686 & 5.57 \mathrm{E}-08 & 834.6025 \\ -688 & 4.30 \mathrm{E}-08 & 643.1552 \\ -690 & 3.31 \mathrm{E}-08 & 495.6235 \\ -692 & 2.55 \mathrm{E}-08 & 381.9337 \\ -694 & 1.97 \mathrm{E}-08 & 294.3229 \\ -696 & 1.51 \mathrm{E}-08 & 226.809 \\ -698 & 1.17 \mathrm{E}-08 & 174.7818 \\ -700 & 9.00 \mathrm{E}-09 & 134.6891 \\ -702 & 6.93 \mathrm{E}-09 & 103.7931 \\ -704 & 5.34 \mathrm{E}-09 & 79.98428 \\ -706 & 4.12 \mathrm{E}-09 & 61.6369 \\ -708 & 3.17 \mathrm{E}-09 & 47.49817 \\ -710 & 2.44 \mathrm{E}-09 & 36.60269 \\ -712 & 1.88 \mathrm{E}-09 & 28.20649 \\ -714 & 1.45 \mathrm{E}-09 & 21.73628 \\ -716 & 1.12 \mathrm{E}-09 & 16.75025 \\ -718 & 8.62 \mathrm{E}-10 & 12.90795 \\ -720 & 6.64 \mathrm{E}-10 & 9.947032 \\ -722 & 5.12 \mathrm{E}-10 & 7.665308\end{array}$

Variation of Equilibrium for fixed $r$

Temperatu Temperatu Cr2+ Conce

873.15 $600 \quad 158.7375$

878.15

$605 \quad 154.9548$

883.15

$610 \quad 151.3036$

888.15

$615 \quad 147.7781$

893.15

$620 \quad 144.3729$

898.15

$\begin{array}{ll}625 & 141.0827\end{array}$

903.15

$\begin{array}{ll}630 & 137.9027\end{array}$

908.15

$635 \quad 134.8282$

913.15

$640 \quad 131.8549$

918.15

$\begin{array}{ll}645 & 128.9784\end{array}$

923.15

$\begin{array}{ll}650 & 126.1948\end{array}$

928.15

$\begin{array}{ll}655 & 123.5003\end{array}$

933.15

$\begin{array}{ll}660 & 120.8913\end{array}$

938.15

$\begin{array}{ll}665 & 118.3644\end{array}$

943.15

$\begin{array}{ll}670 & 115.9162\end{array}$

948.15

$\begin{array}{ll}675 & 113.5437\end{array}$ 
Fig 6

Small

version

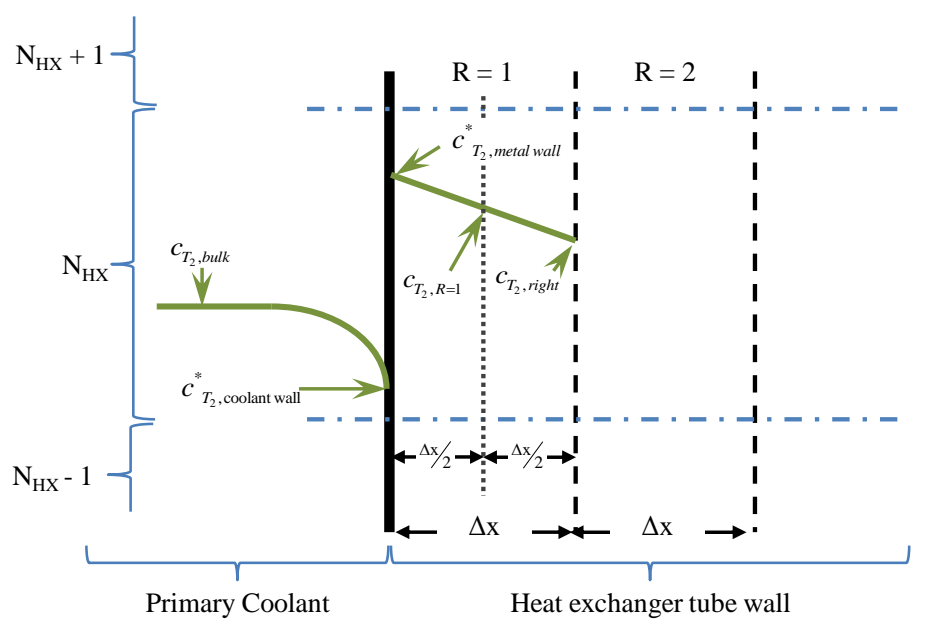


Fig 6

Large

version

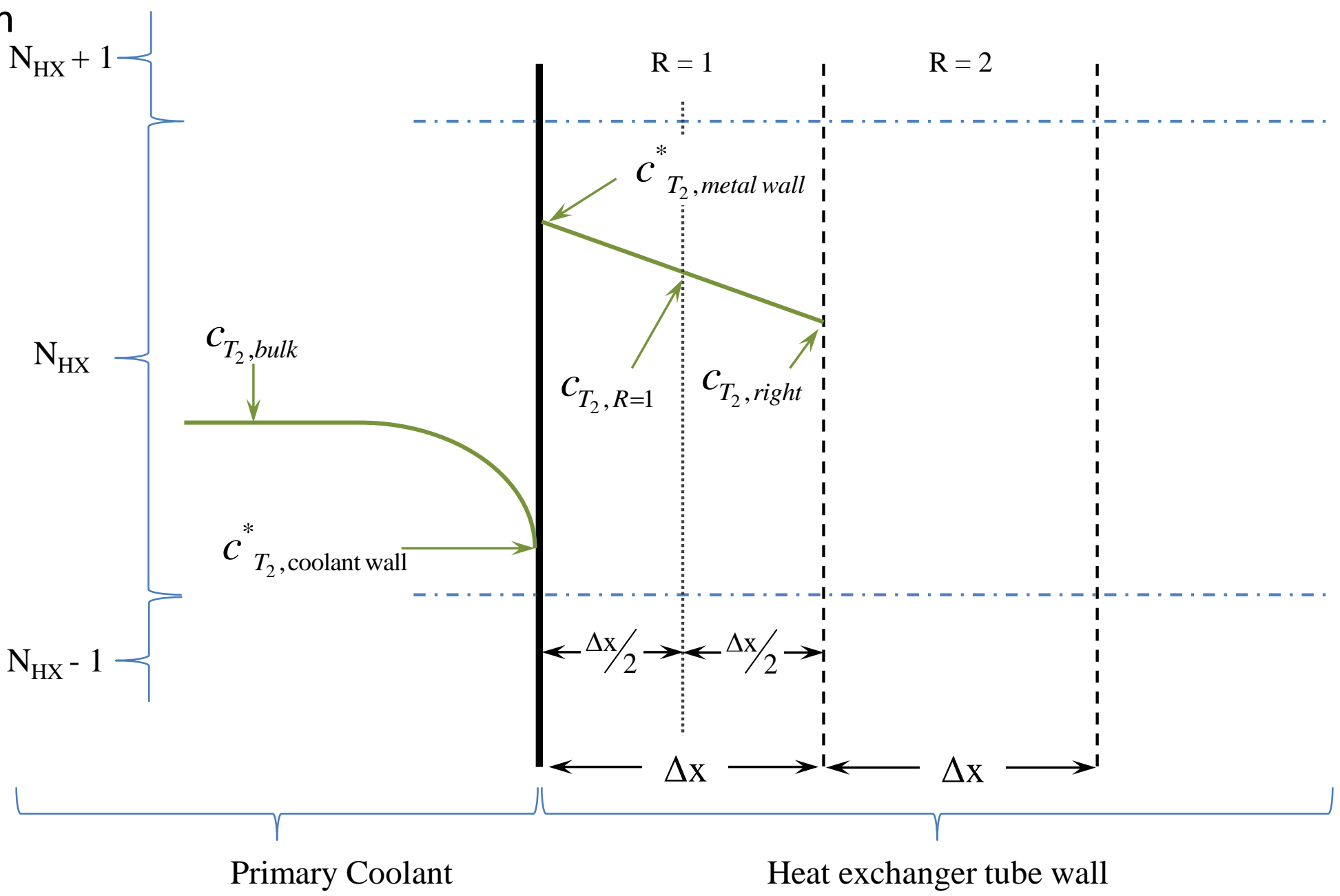


Benchmarking TRIDENT against the experiments from Fukada, 2006 in JNM vol 358

$\mathrm{mm}$

Salt Thickness

Ni membrane thickness

$\mathrm{T} 2$ input pressure $(\mathrm{Pa})$

Outlet pressure $(\mathrm{Pa})$

$1.01 \mathrm{E}+05$

Temp (K)

973.15

Metal elements

Salt elements

Hour Fraction

Fourier Number set to

0

15

20

2

20

0.1

0.5

Figure 7

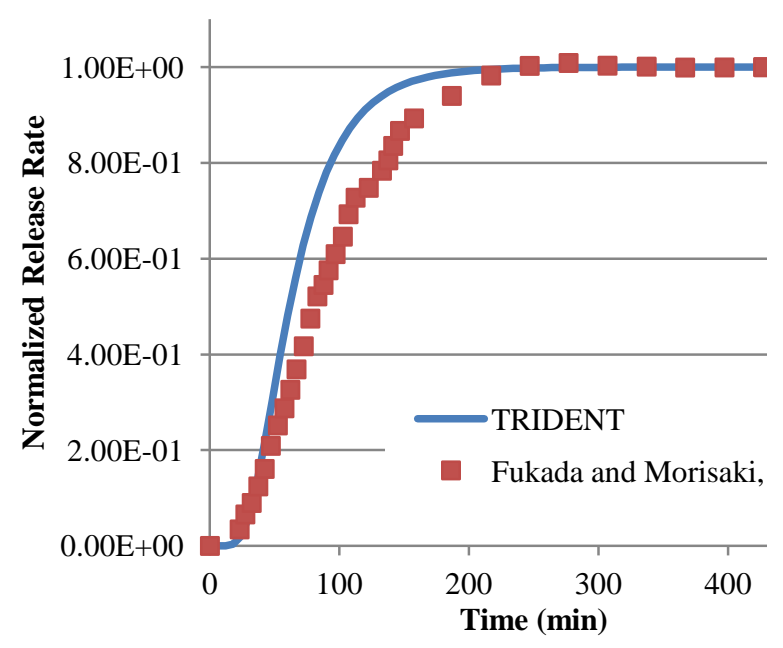

Minutes

\section{6}

12

18

24

30

36

42

48

54

60

66

72

78

84

90

96

102

108

114

120

126

132

138

144

150

156

162

168
T2 Flux out of salt surface (mol H2/m2-s)

$1.71 \mathrm{E}-13$

3.49E-10

9.31E-09

5.65E-08

$1.71 \mathrm{E}-07$

3.56E-07

5.90E-07

8.46E-07

$1.10 \mathrm{E}-06$

$1.34 \mathrm{E}-06$

$1.56 \mathrm{E}-06$

$1.75 \mathrm{E}-06$

$1.92 \mathrm{E}-06$

2.06E-06

$2.18 \mathrm{E}-06$

$2.28 \mathrm{E}-06$

2.36E-06

2.44E-06

2.49E-06

$2.54 \mathrm{E}-06$

$2.59 \mathrm{E}-06$

2.62E-06

2.65E-06

2.67E-06

2.69E-06

2.71E-06

2.72E-06

2.73E-06 


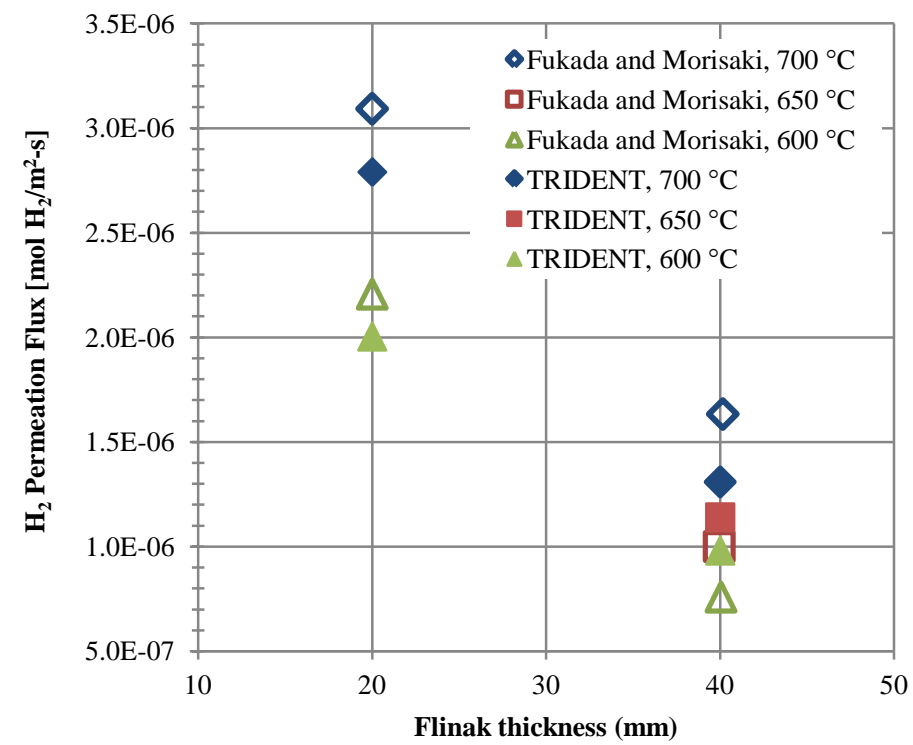

Fig. 8. 


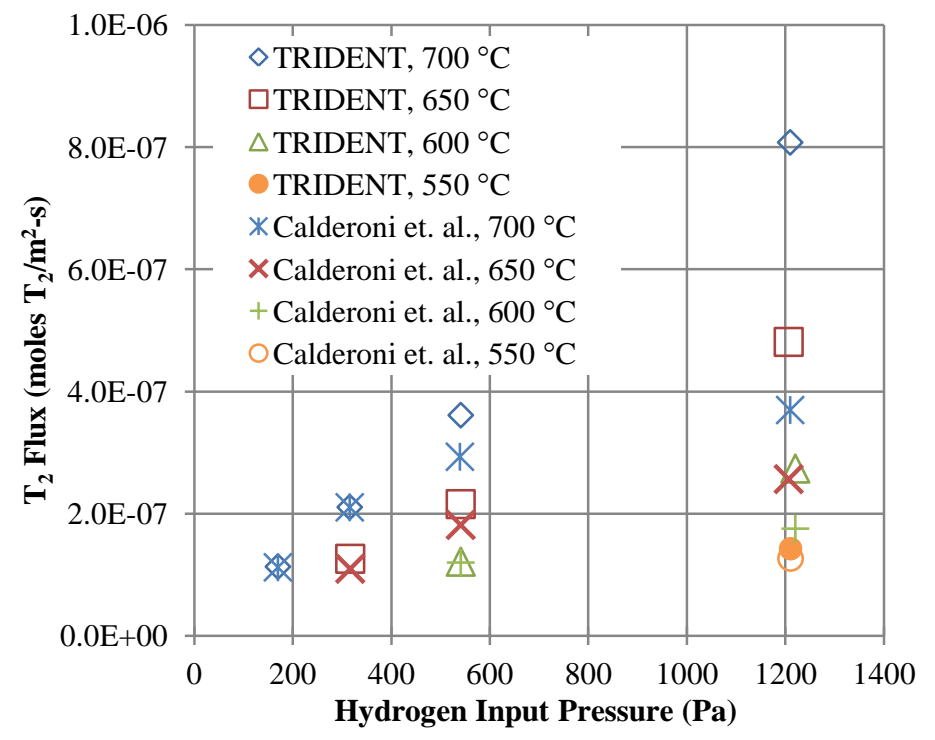

Fig 9 
Figure 10

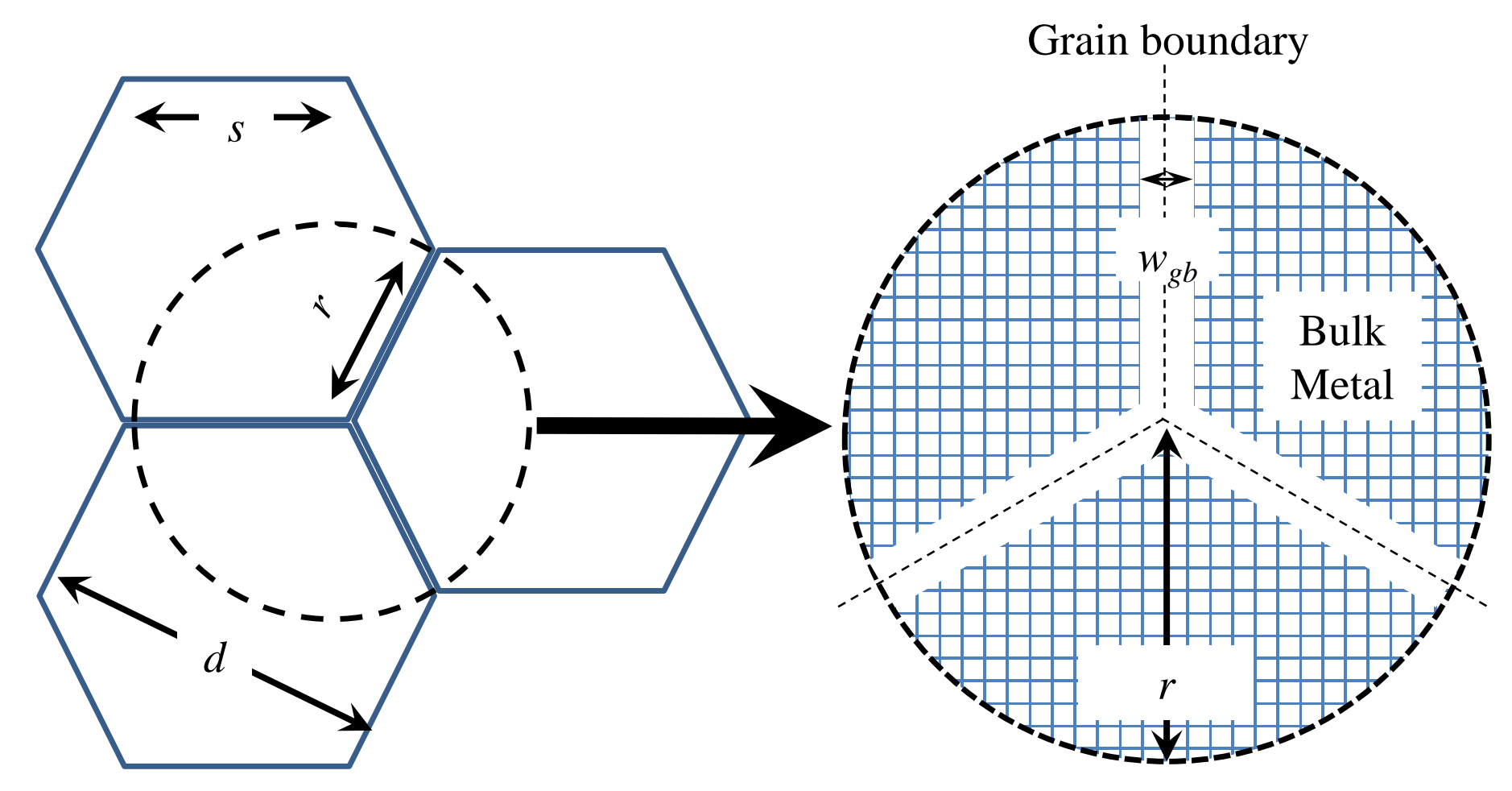


Figure 11: Image from Keiser, 1977.

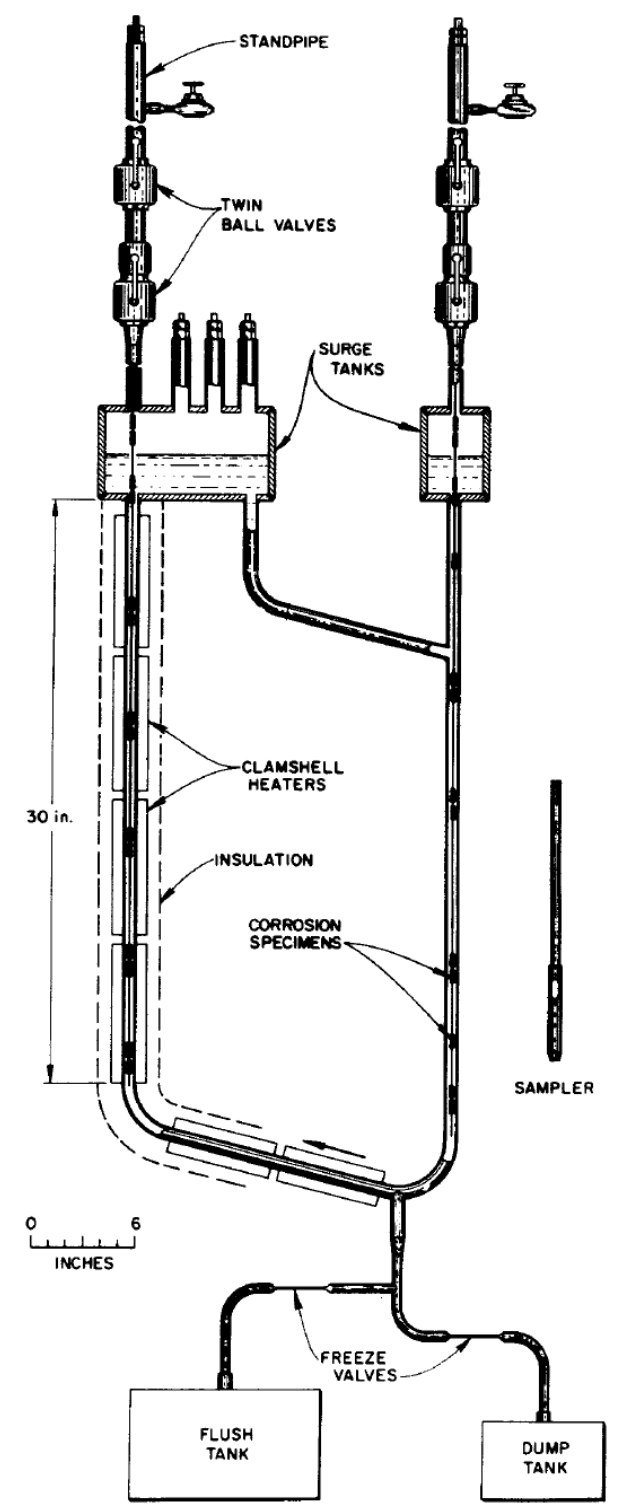




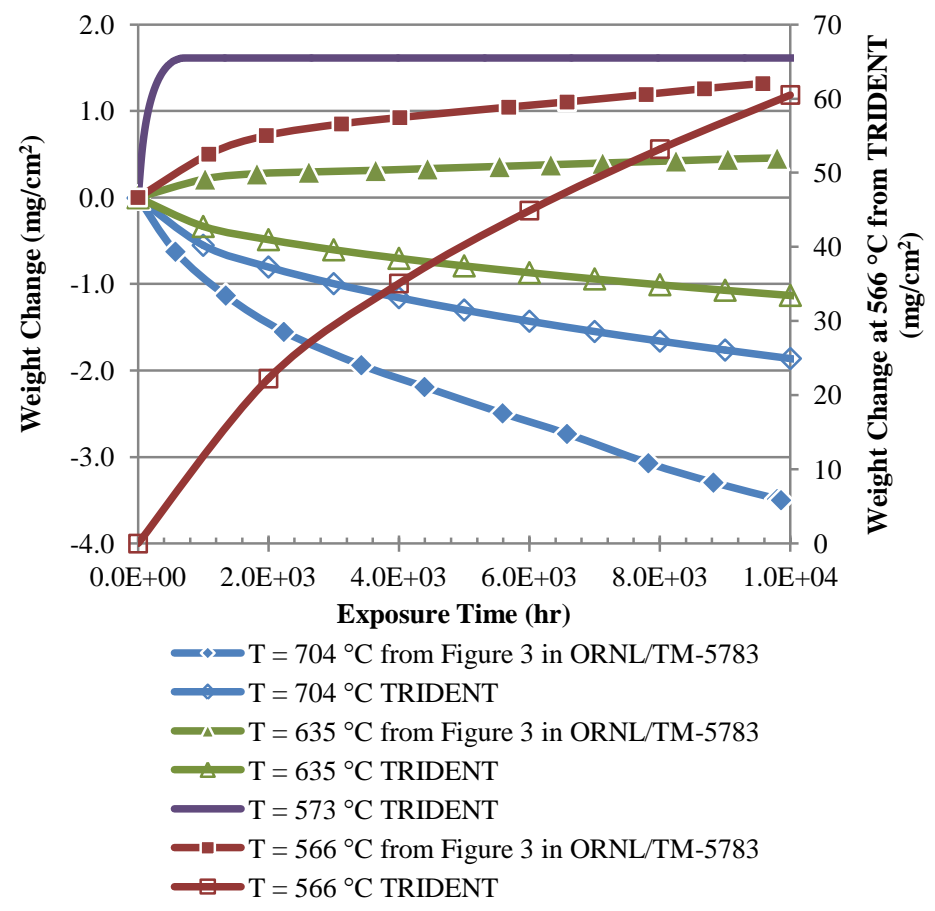

Fig 12 